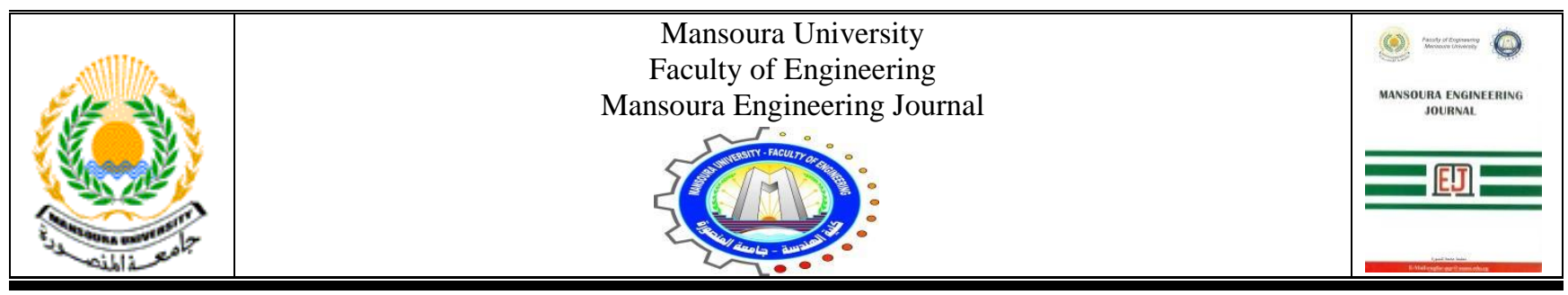

\title{
Design Visions for the Future of Contemporary Mosque Architecture between Identity and Originality
}

\author{
KEYWORDS: \\ Identity, \\ Contemporary, \\ Mosques of the Future, \\ Originality, \\ Design Visions.
}

\author{
Shimaa Abd El-Majeed Ibrahim
}

Abstract - Mosque architecture is one of the most important features of Islamic architecture throughout the ages, and it is a center of intellectual and religious radiation in which Islamic civilization grew, but if there is any change affecting the identity of the mosque or its traditional concept and sacred personality influenced by advanced technology from the West with its objectives and ideas in an attempt to take advantage of the modern possibilities available, forgetting the main function and cultural spirit of mosques that annul the original values of our architecture and obliterate the local identity, privacy and belonging of the cultural heritage of the city.

By identifying proposals and visions about mosque architecture and development, with regard to the philosophy of mosque design, spatial characteristics, visual dimensions, community options for the site, and building technology, the research addresses current trends and expected future visions of the architecture of contemporary mosques, which are an important pillar for Muslim communities in all Throughout the world, it remains an important center for spiritual, moral and cultural life in Muslim societies, despite the preservation of its overall spatial, visual, cultural, social and spiritual characteristics over the centuries, but the design of contemporary mosques has undergone various transformations that emphasize its centrality and adaptability to Islamic community developments.

The problem of research comes in: the loss of heritage identity and originality in the designs of contemporary Arab and Islamic architecture mosques, which are characterized by the weakness of the new mosque architecture designs by the requirements: functional, security and safety, environmental and aesthetic, so that they meet the needs of the worshippers and combine between 'originality' and 'creativity' in Saudi Arabia.

The research includes five main parts: the first part of the presented in terms of objectives, problems and methodology, while the second part discusses the general concepts and four directions of the architecture of the mosques of the future, the main components and design considerations and requirements for evaluating the architecture of contemporary mosques, and The third part presents the practical framework for evaluating the standards and design requirements on two mosques with different environments in (Riyadh city and Medina), to develop a governing framework for the architectural design process of the architecture of contemporary mosques, and The fourth part includes: presenting the results of the field survey of the views of worshippers and users in the mosques of the school districts to reach the general population's satisfaction with the mosques, and the research ends in the fifth part: The results of the questionnaire, the summary and the most important results and recommendations. 


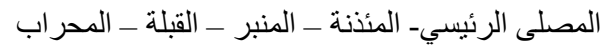

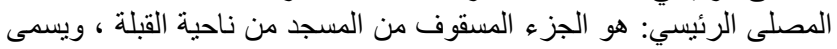
(بيت الصلاة): وهي تحمي المصلين من العوامل الجوية (الثمس والرئل الرياح و المطر).

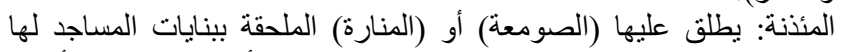

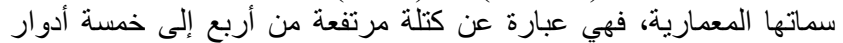

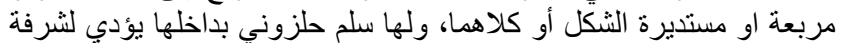

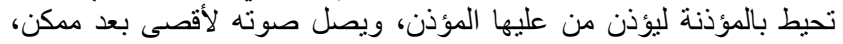

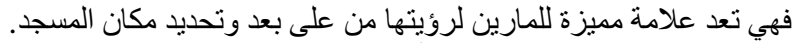

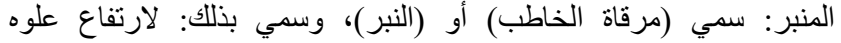

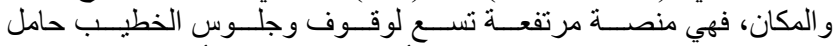

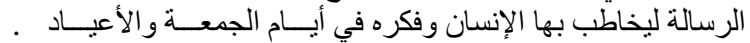

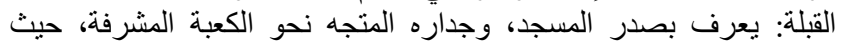
يصلي المصلين تجاهها فتكون وجو ههم ناظره في بيت الله في ذللك المكة المنة

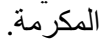
المحراب: هو تجويف نصف دائري في الحائط مجوف أو بارز ليميز اتجاه

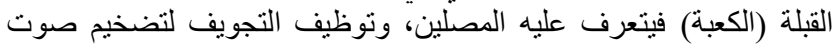

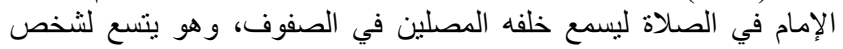

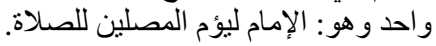

$$
\text { ب- عناصر تكمبلية : بشمل على : }
$$

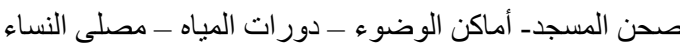

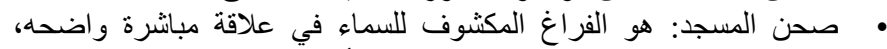

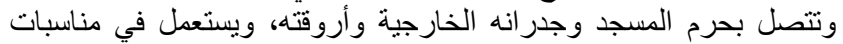

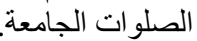

أماكن الوضوء: أحواض مخصوة اضوفة لغرف المياه، ومقاعد يتقدمها حنفيات الوضوء مزودة بأنابيب ومجاري الوضون المياه.

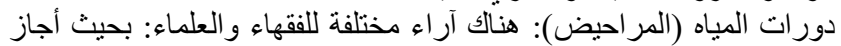

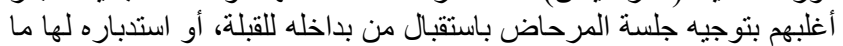
دام هنالك حائط حائل مرتفع يستر المئه أسفل الإنسان.

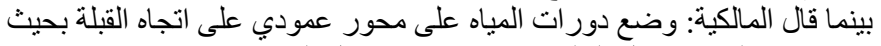

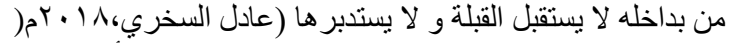

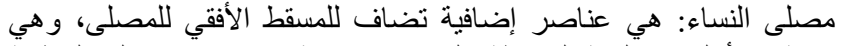

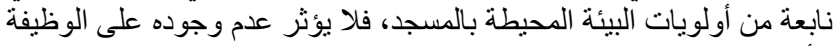
الأساسية للمسجد (الصلاة).

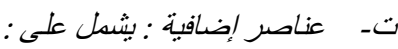

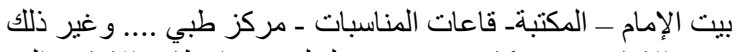
بيت الإمام: هو مكان مخصص لجلوس وانتظار الإمام (المؤذن) بين

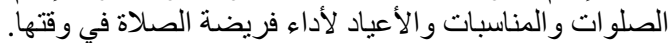

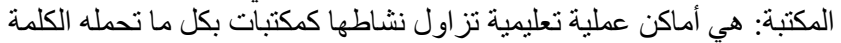

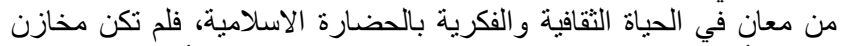

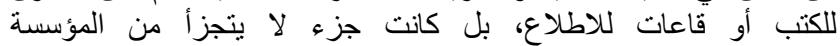

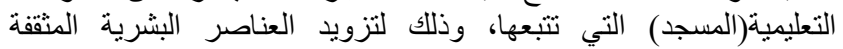

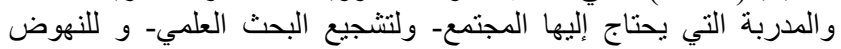

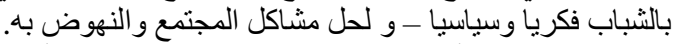

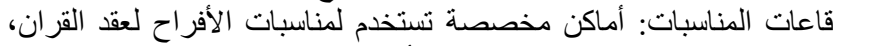

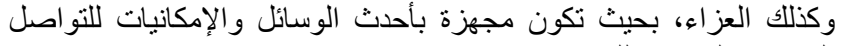

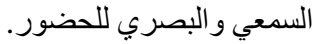

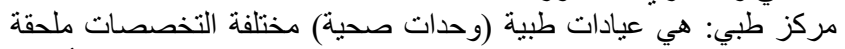

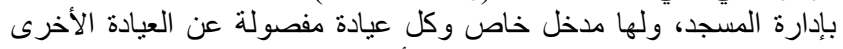
لخدمة وعلاج المرضى الفقر اء بالمجان أو بسعر رئ رمزي.

IV الاعتبارات والمتطلبات التصميمية لتقييم عمارة المساجد المعاصرة: تم استخلاص مجموعة من الأسس التصميمية والمعايير التخطيطية كوسائل

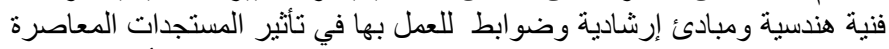

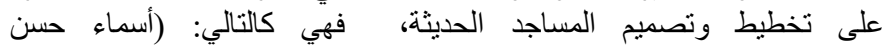

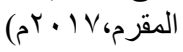

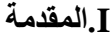

حتل عمارة المساجد عبر مختلف العصور الإسلامية موقع الأولوية

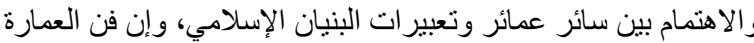

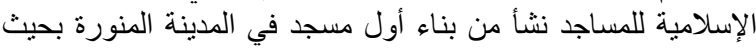

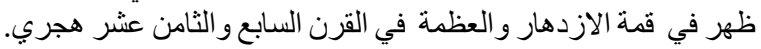

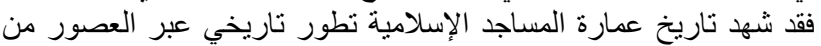

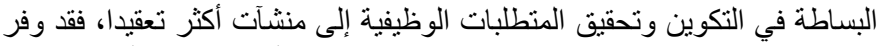

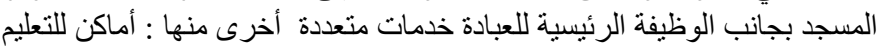

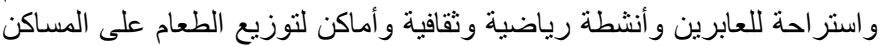
و الفقر اءك....... و وغير ها. لمابن.

\section{تعاريف ومفاهيم عسامة.II}

أ- الهوبية

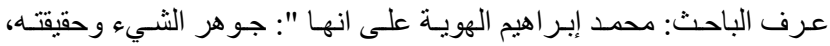

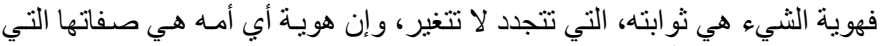

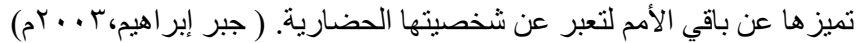

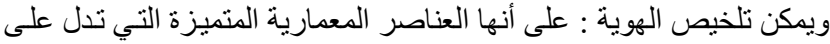

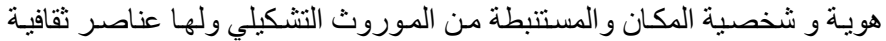

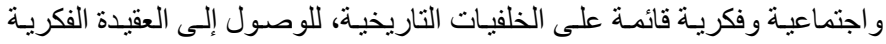

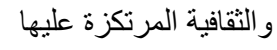

ب- بالألة

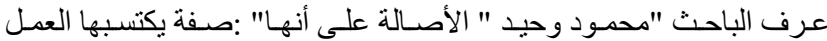

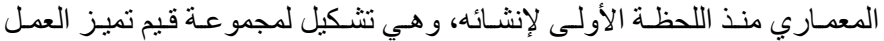

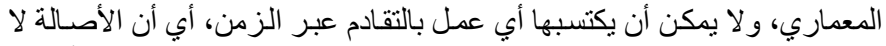

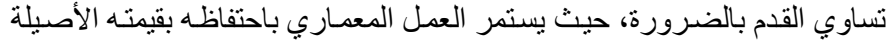

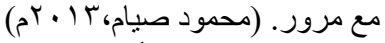

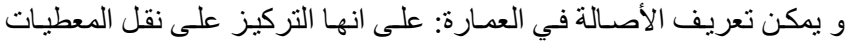

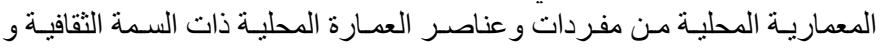

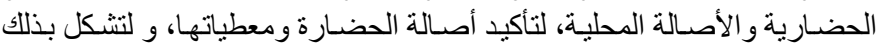

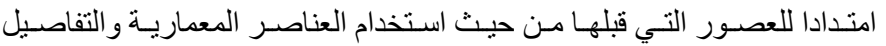
و المادة البنائية.

تـ- التبارات الفكرية والآثار السلبية المؤثرة على الهوية والأصسالة لعدارة

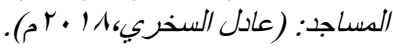

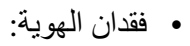

يتم طمس وفقدان هوية العمارة المحلية من خلال الانقياد الأعمى وفسـخ القيم

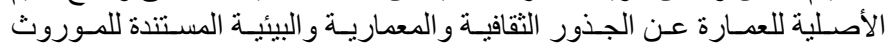
الحضاري للمدينة.

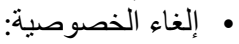

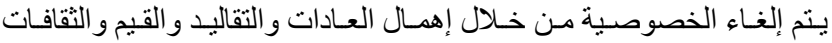

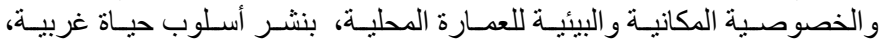

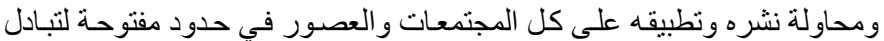
الأفكار و الخدمات و الامو النماه و السلع.

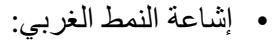

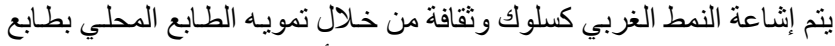

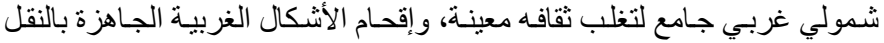

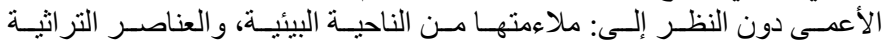

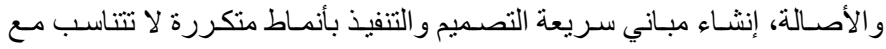

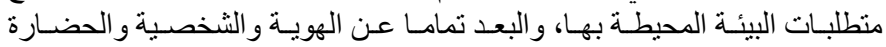

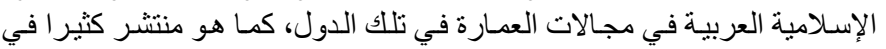

أو اخر القرن العشرين الحالي في دول الغنية اقتصاديا: كدول الخليج والسعودية.

المكونات الرئيسية في عمارة المساجد الإسلامية المعاصرة: (شيماء

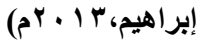

$$
\text { أ- عناصر رئبيسية : بشهل على : }
$$




$$
\text { أ - مسجد الدعدور - الرياض ـ المملكة العربية السعودية : }
$$

• التعريف للمسجد:

يعد مسجد المعمور، إحدى مبادرات شركة المساجد المتكاملة لعام

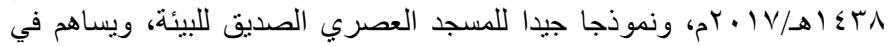

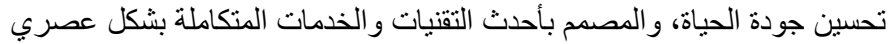

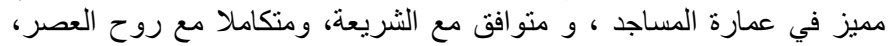
ومحتفظا بإرث الماضي وفق مفهوم الاستدامة المنكاملة.

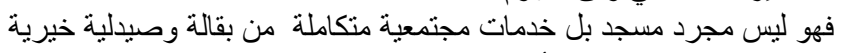
وصر اف آلي وحديقة ورياض أطفال وممشى وملعب للكره الطائرة للكبار ، وهي مشاريع مستدامة ووقفية للمسجد.

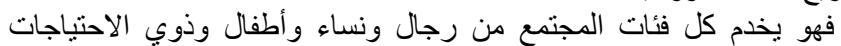

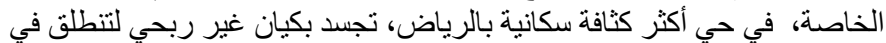

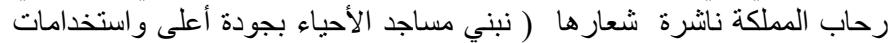

أنفع وتكلفة أقل).

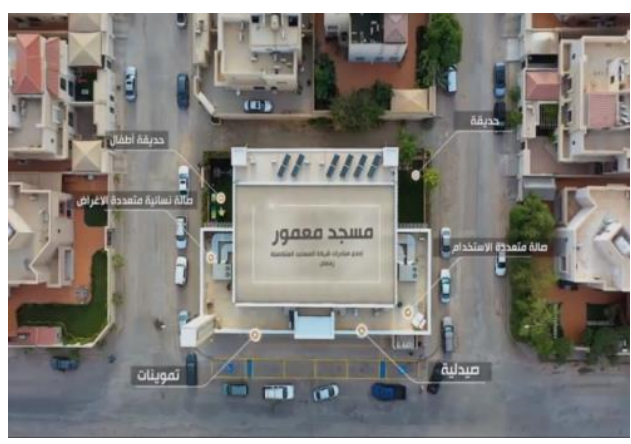

شكل رقم (1 ) : يوضح موقع عام لمسجد المعمور بين الأحياء

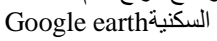

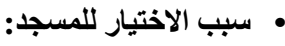

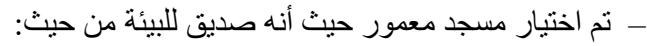

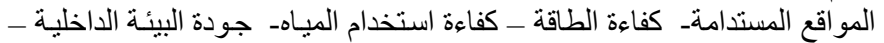

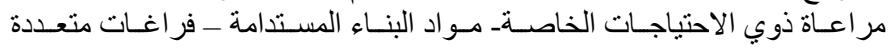
الاستخدام - الامتداد المستقبلي.

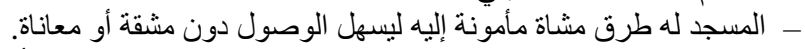

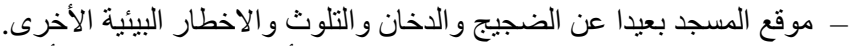

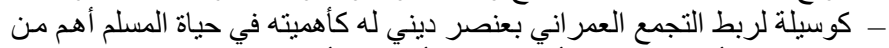

ربطه بعناصر أخرى ترفيهية أو اجتماعية أو ثقافية أو روحية ونية وغيره.

\section{• موقع المسجد الجغرافي :}

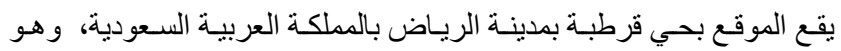
موقع استر اتيجي داخل منطقة سكنية تقع داخل حي سكني ليخدم العديد من سكان النسان

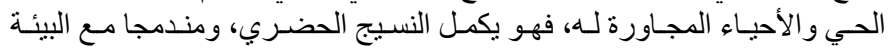

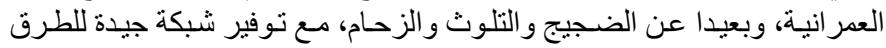

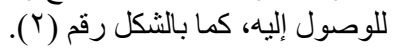

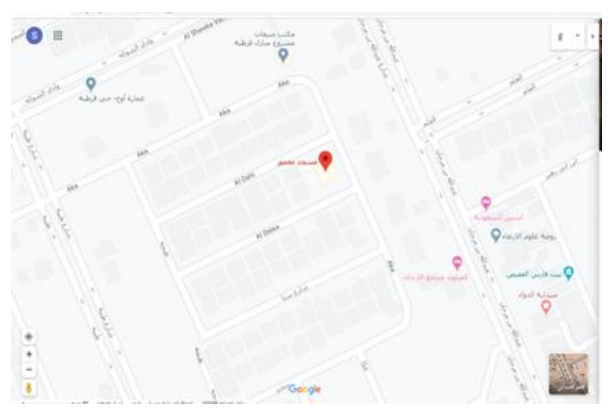

شكل رقم (r ): يوضح موقع عام لمسجد المعمور Google earth
أـ الاعتبارات الوظبفية:

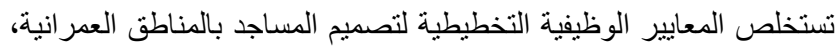

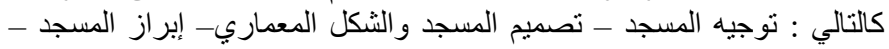

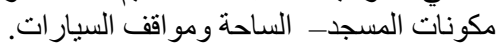

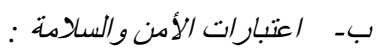

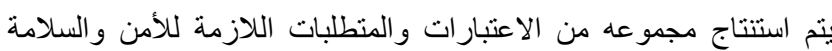

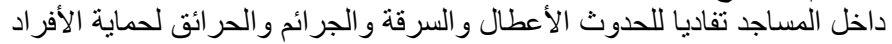

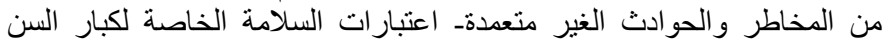
وذوي الاحتياجات الخاصة.

ت- الاعتبارات البيئية :

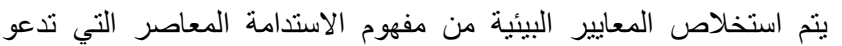

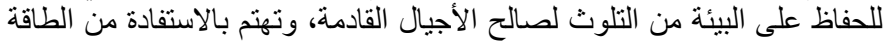

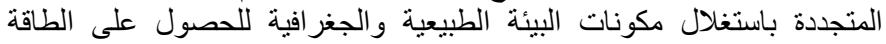

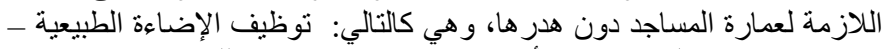

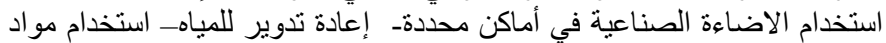
البيئة المحلية.

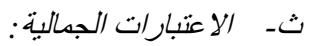

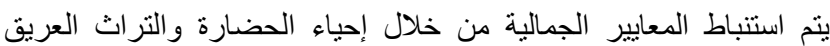

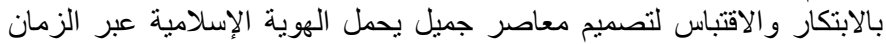

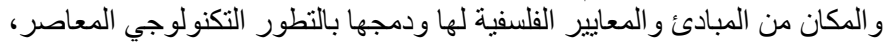

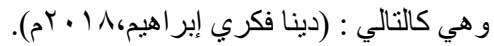

• التجريا : يمثل التجريد و التصميم ارتباطا وثيقا، فكلما كان التشكيل بتصميم

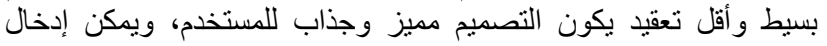
تشكيلات جديدة تتناسب مع الهوية و الحضارة الإسلامية لإضفاء سمه لإسه

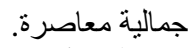

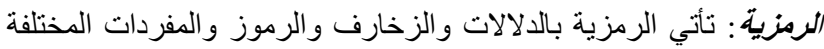

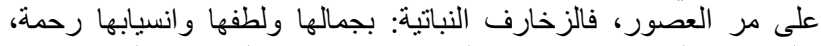

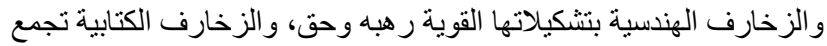

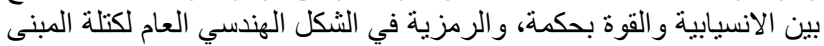

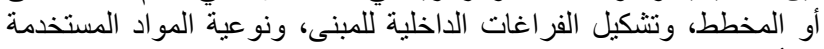

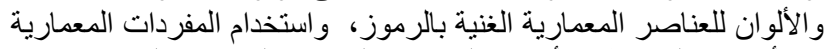

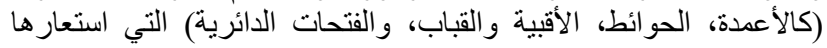

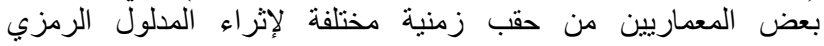
لمقتر حاتهم التصميمية. النفعية : تمثل المنفعة والجمال ارتباطا وثنيقا، فالمنفعة بدون الجمال ينتج

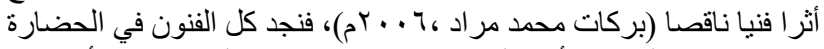

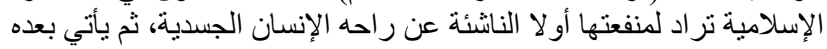

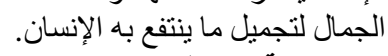
الاستمرارية : تمثل الاستمر ارية في الحفاظ على الإنى قيمة الموروث على على فترات

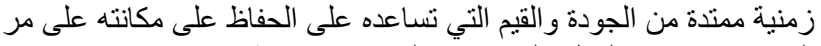

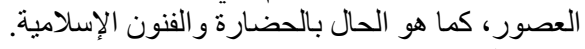

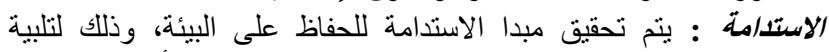

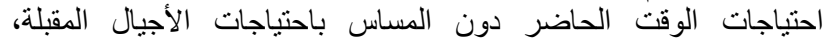

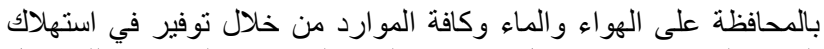

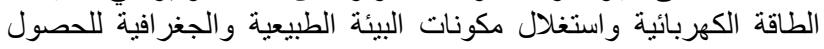
على مباني صديقة للبيئة.

V . راسة وتحليل للمساجد المعاصرة وفقا للاعتبارات و المتطلبات التصميمية

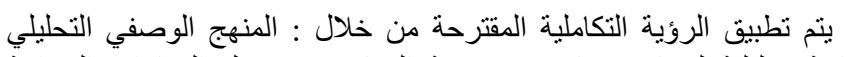

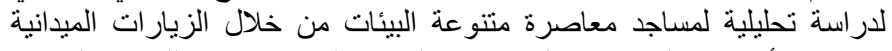

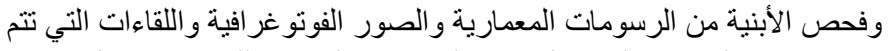

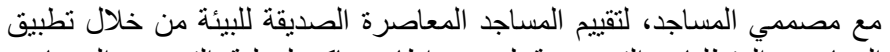

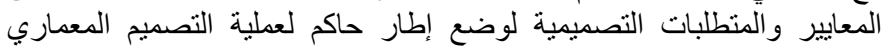

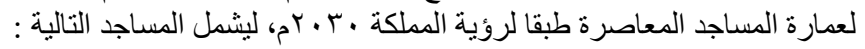




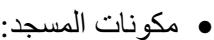
|

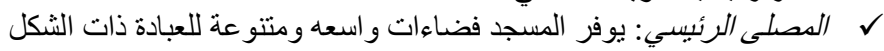

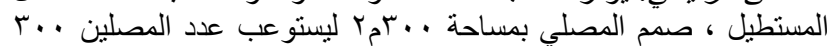

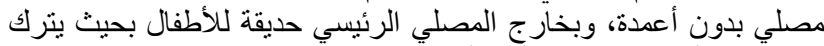

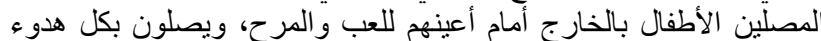

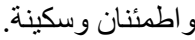

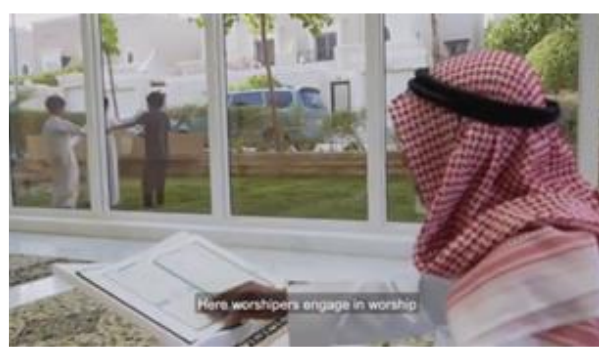

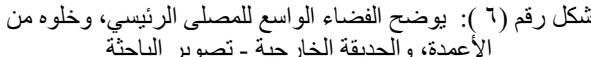

ل المئنة: تم استبدالها بمنارة على الثكل المربع كالمنار ات الغربية التقليدية

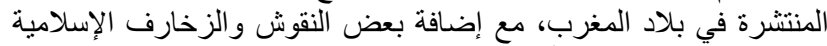

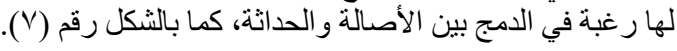

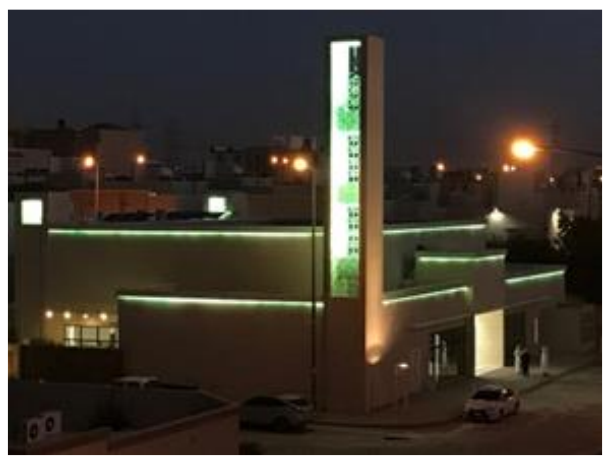

شكل رقم ( ا ): يوضح المنارة ذات النقوش و الزخارف الإسلامية و إضاءة ليلية جميلة ـ تصوير الباحثة البنار

القبلة : يقع في جدار القبلة بالوسط. $\checkmark$

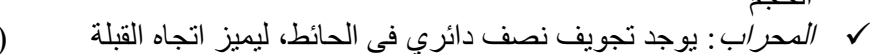
الكعبة ) فيتعرف عليه المصلين بالمصلى الرئيسي للمسجد، كما بالثكل (^).

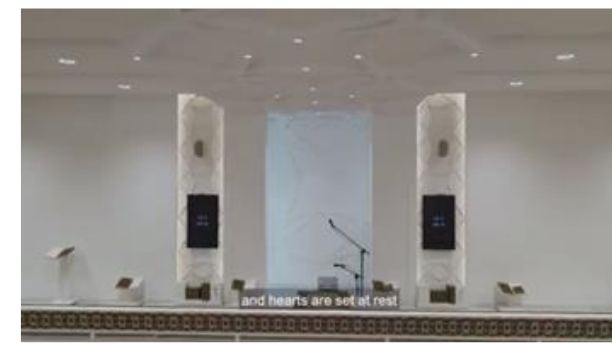

شُكل رقم (^ ): يوضح المحر اب ذات تجويف نصف دائري في الحائط ـ

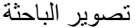

\$

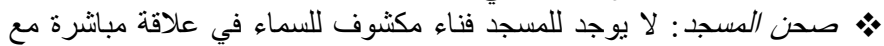

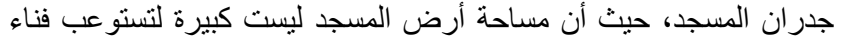
مكثوف بين جدران المسجد.
• الاعتبارات والمتطلبات التصميمية لتقييم عمارة المساجد المعاصرة : أـ الاعتبار ات الوظبفية:

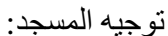

تم توجيه المسجد حسب الاتجاه نحو القبلة عن طريق رواق الصلاة حيث

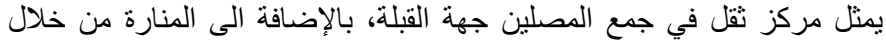

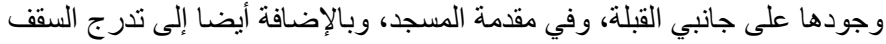
في المسجد بالنسبة لمساحة و عدد المصلين بالمسجد، كما هو موضالئح بالئه الثكل رقم

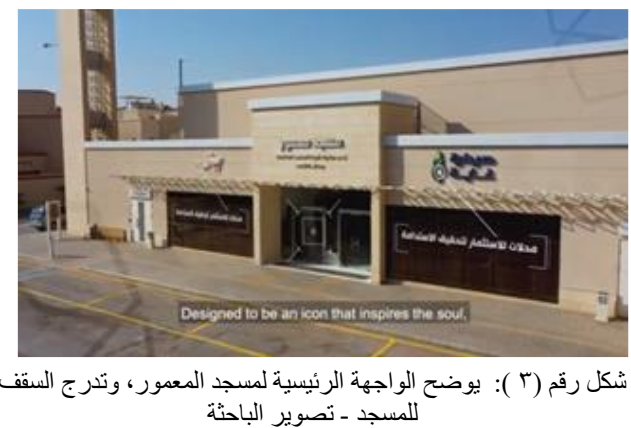

• تصميم المسجد والثكل المعماري:

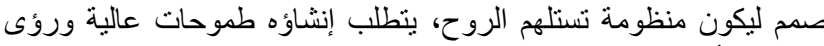

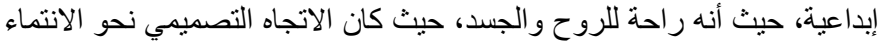

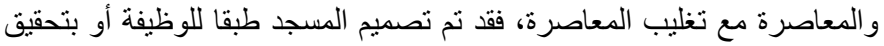

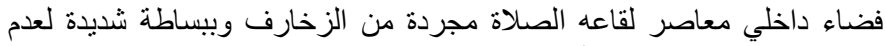

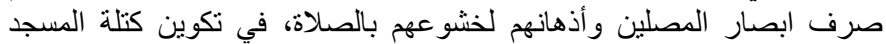
و المنارة تثميز بالبساطة في التصميم و عدم التكليف، كما هو موضح فئح بالثكل رقم

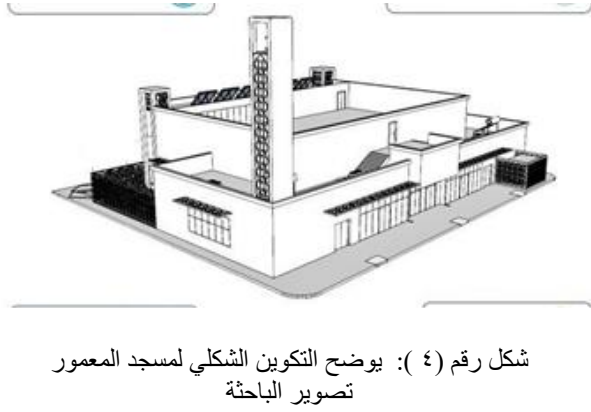

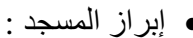

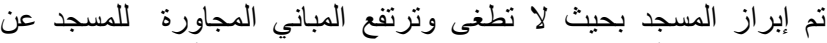

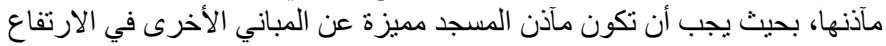

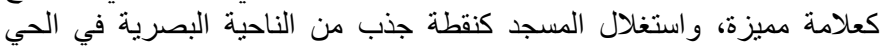

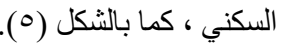

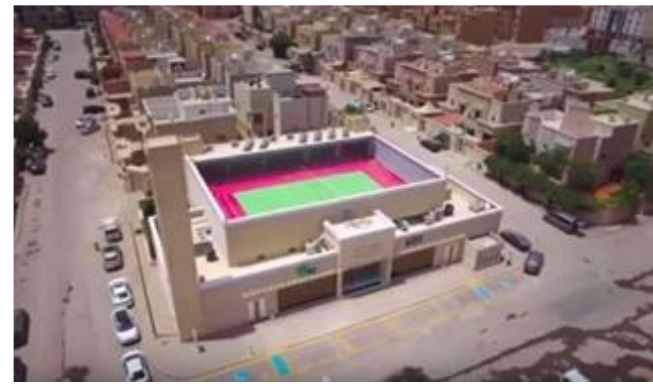

شكل رقم (0 ): يوضح إبراز المسجد بين المباني السكنية المجاورة

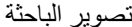




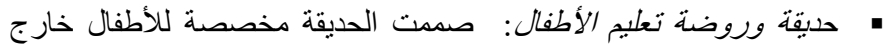

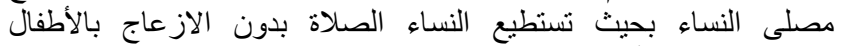

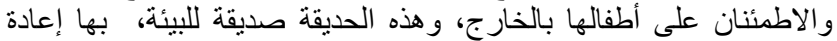
تدوير للمياه الوضوء ومياه الأمطار، كما بالثكل رقم (r ( )

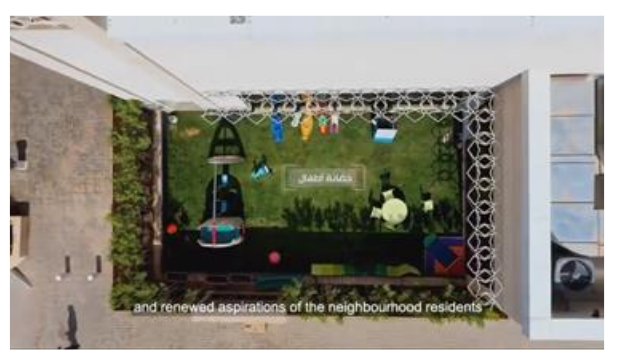

شكل رقم (r I ): يوضح الحديقة وروضة الاطفال خار ج مصلى النساء Google earth

مضمار الجري وملعب للكره الطائرة للكبار: يحتوي أعلى المسجد بالسطح

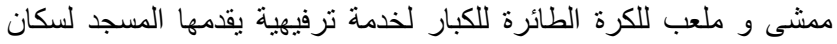

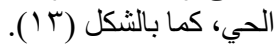

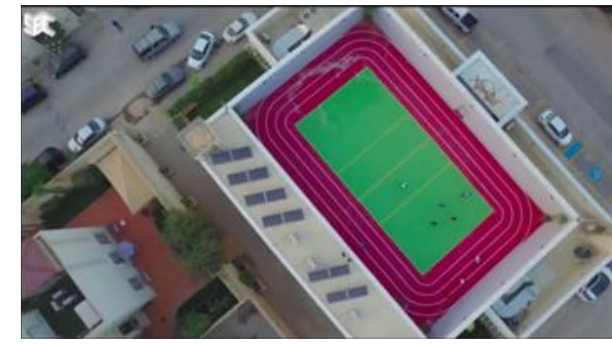

شكل رقم (T) ) : يوضح ملعب الكرة الطائرة المستخدم بأعلى سطح Google earth المسجد ( )

• غرفة الإمام: يحتوي على مكتب المؤذن لإقامة الصلوات في توقيتها المحدد،

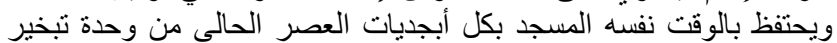

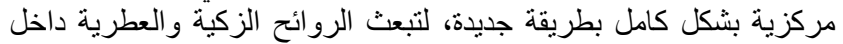

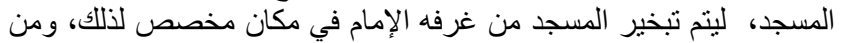

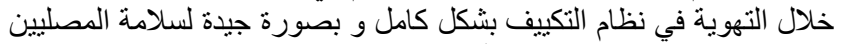

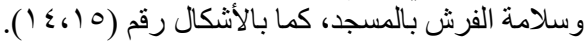

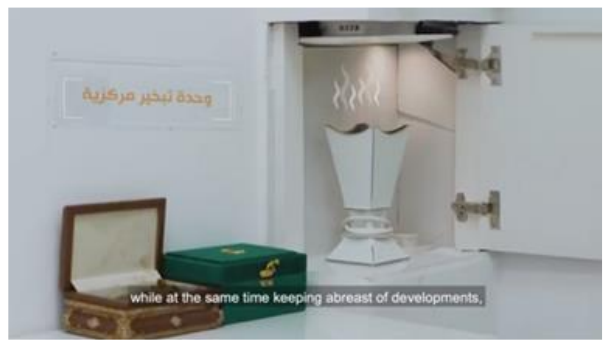

شكل رقم (ع ا ): يوضح مكان مخصص للتبخير الآلي بالمسجد بالكامل من داخل غرفة الإمام- تصوير الباحثّة

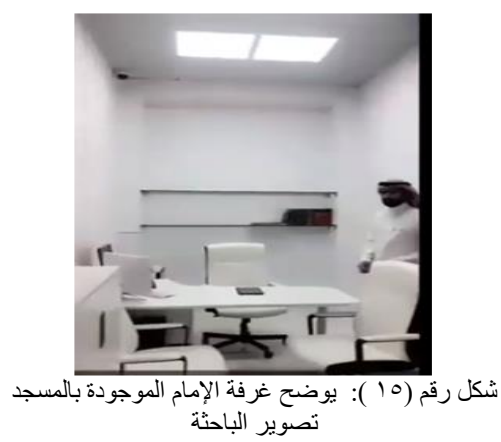

• دورات المباه: هي ملحقة داخل المسجد وخارج المصلى الرئيسي، لتكون

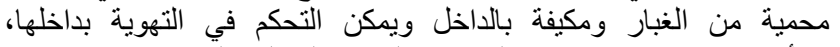
و الأرضية مصنو عة بدور ات المياه من الخشب المبن المعالج بالتصنيع.

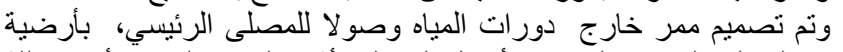

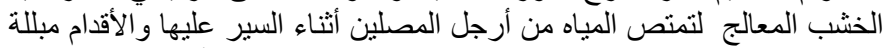

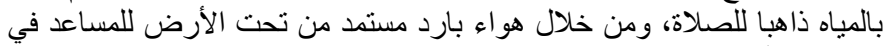

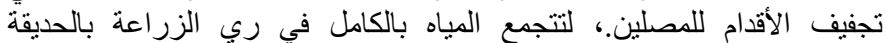

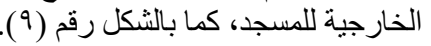

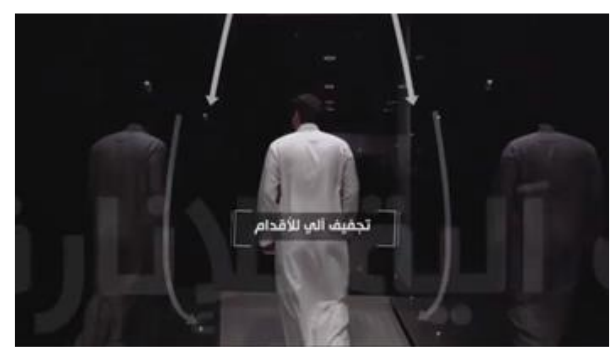

$$
\text { شكل رقم (9 ): يوضح ممر التجفيف الآلي للأقدام بالمسجد }
$$

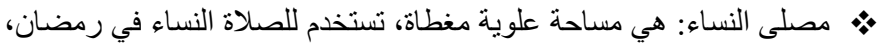

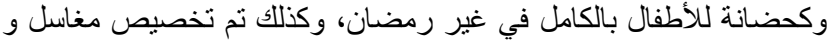
دور وات مياه خار ج مصلئ النساء.

|

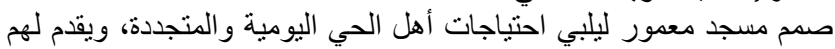

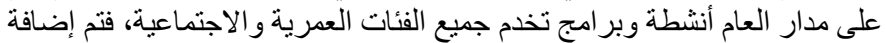

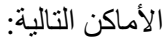
• صالة داخلية لحفظ القرآن الكريم: لتعليم المتعلمون لقر اعة وحفظ كتاب الله في

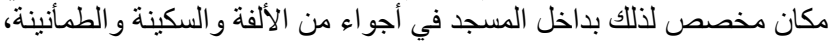

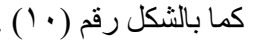

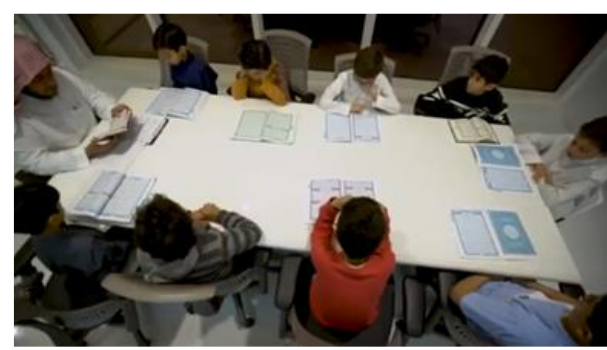

شكل رقم (• ( ): يوضح صاله لإقامة الدروس الدينية وحفظ القرآن الكريم داخل مسجد المعمور ـ تصوير الباحثة البنة

" ت صاله متعددة الاستخدمات وقاعة /جتماعات :

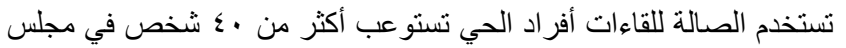

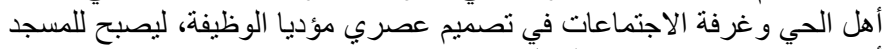
أكثر من معنى و غاية، كما بالشكل رقم (1) (1).

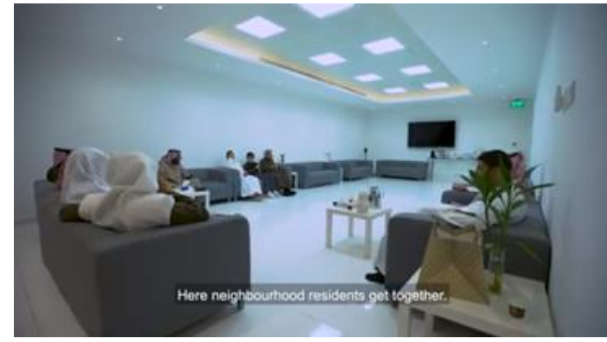

شكل رقم (11 ): يوضح صالة متعددة الاستخدامات داخل المسجدتصوير الباحثة 
م توفير أماكن للار اجات الهو ائية بخارج مسجد معمور لتسهيل حركة الوصول

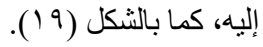

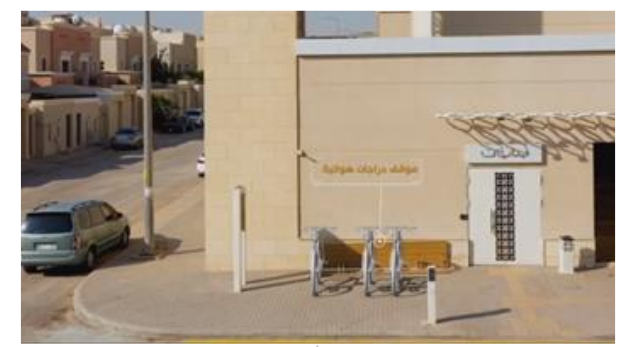

شكل رقم (9 19 ): يوضح توفير أماكن للار اجات الهو ائية خارج المسجد تصوير الباحثة المانة

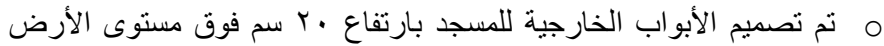

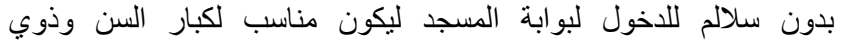

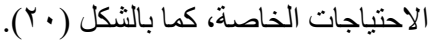

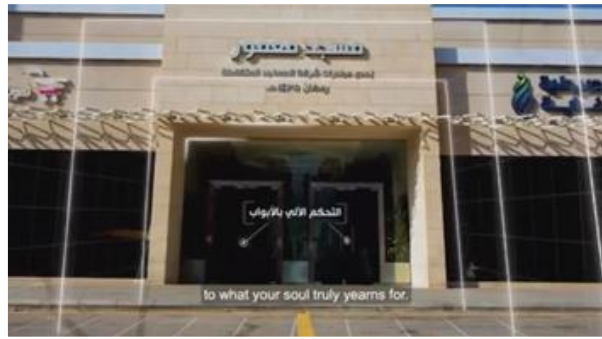

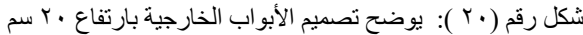

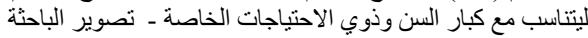

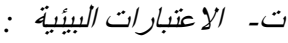

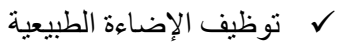
يتأثر الثكل المعماري لقاعة الصلاة بالمساجد بالتفاعل مع الضوء الضهاء الطبيعي طبقا

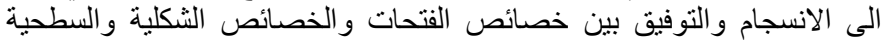

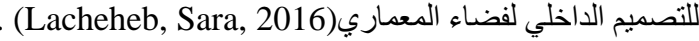

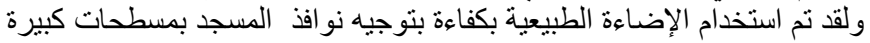

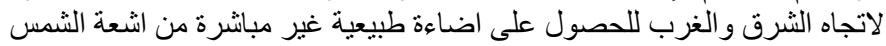
التي لا تجلب الحرارة، ولعدم تشتيت المصلين أثناء الصلاة، كما بالشكل رقم

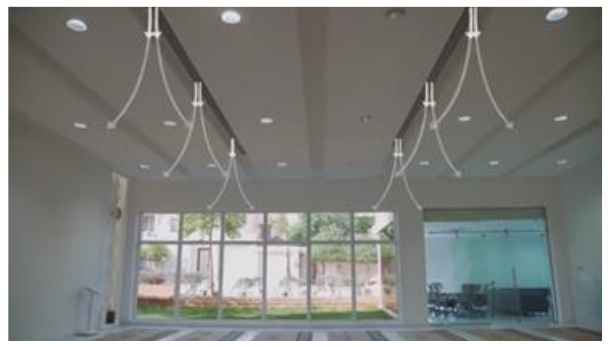

شكل رقم (Y) ): يوضح المسطحات الكبيرة للنو افذ لتوفير الإضـاءة الطبيعية- تصوير الباحثة الكنيل

و ل استخدام الاضاءة الصناعية في أماكن محددة

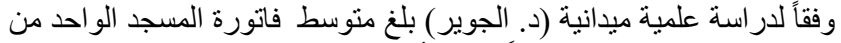

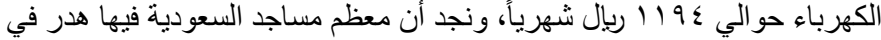

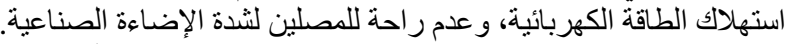

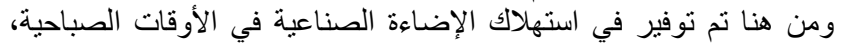

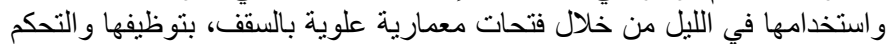

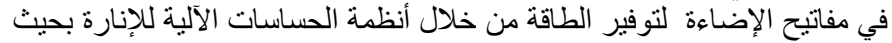

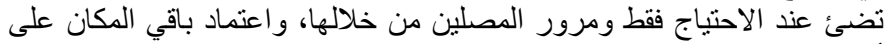

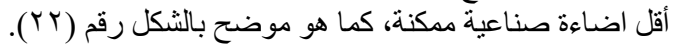

• الساحة ومو اقف السبار ات:

تم مراعاة وجود ( صالة ) فاصلة بين البوابة الخارجية للمسجد والبوابة

الداخلية للمسجد (المصلى الرئيسي.)

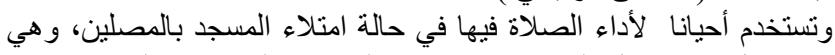

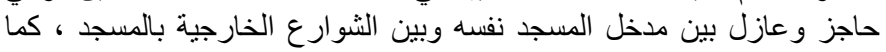

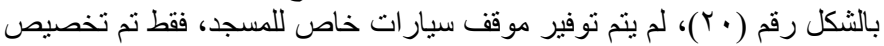
المسجد لخدمة أهل الحي بالمجاور لتوفير موت السكنية المحيطة بالمسجد.

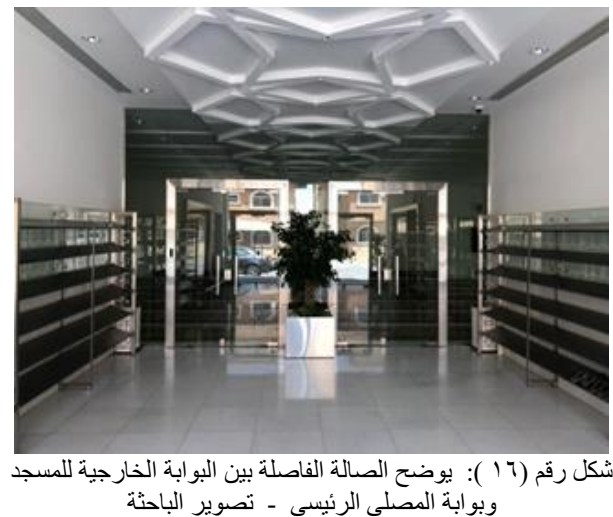

ب- اعتبارات الأمان والسلامة :

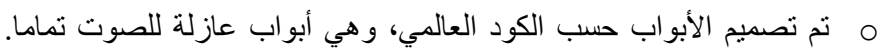

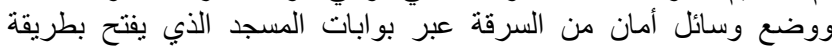

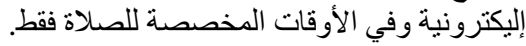

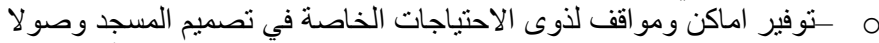

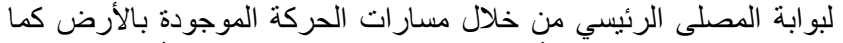

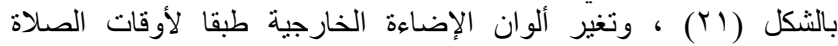

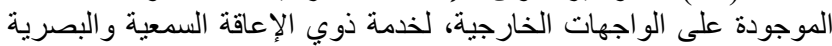

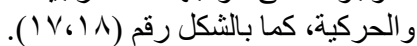

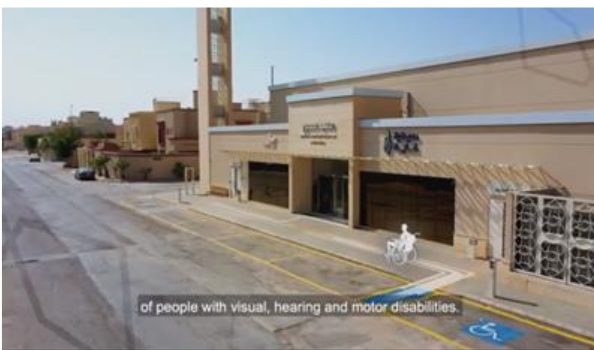

شكل رقم (IV) ): يوضح أماكن المو اقف ومسار ات الحركة الخاصة لذوي الاحتياجات الخاصة. تصوير الباحثة

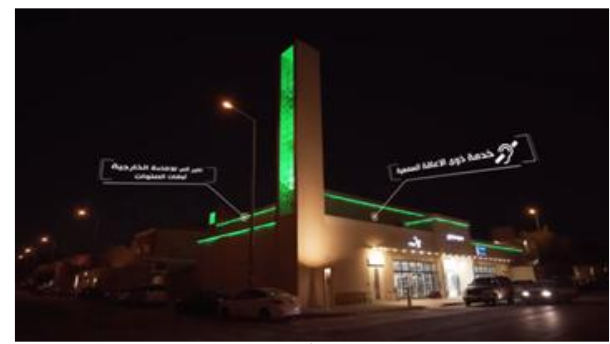

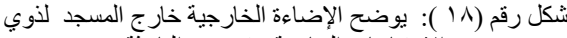
الاحتياجات الخاصة_ ت تصوير الباحثة

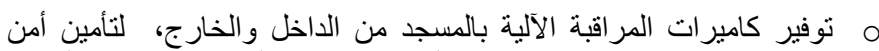

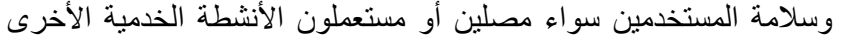
م تم عمل مسار جانبي لخروج المصلين في الصفوف الأولى دون انتظار المصلين في الصفوف الخلفية. 
و الاستفادة من كمية الأمطار التي تهطل على مدار العام، ليتم تجميع المياه

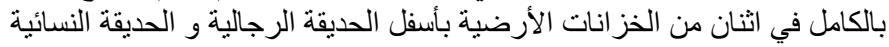

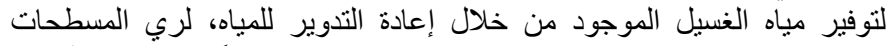

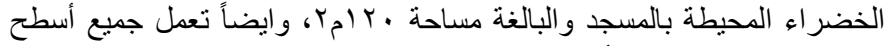

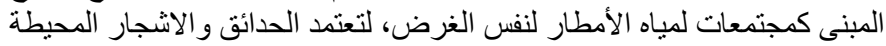

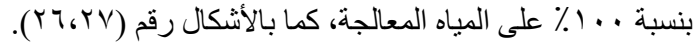
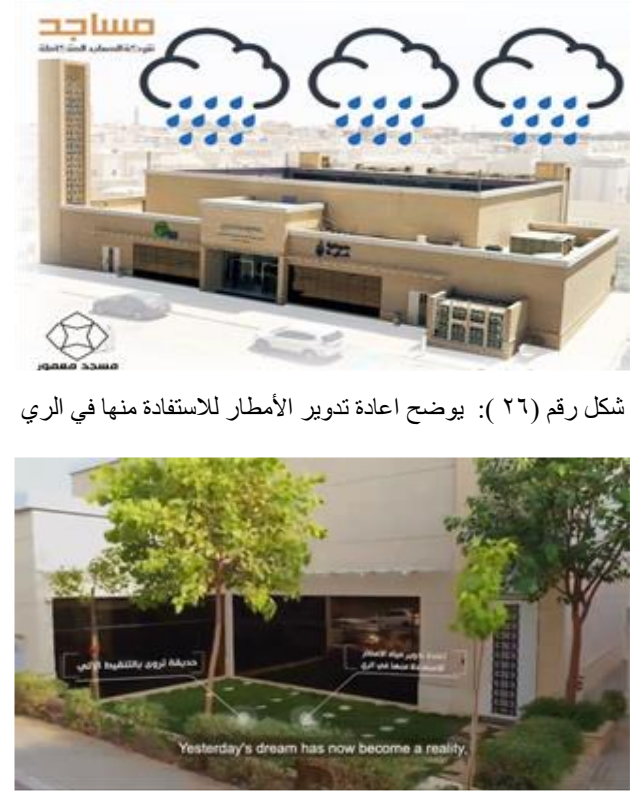

شكل رقم (YV) ): يوضح اعادة تدوير المياه الرمادية للاستفادة منها في

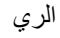

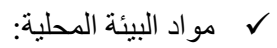

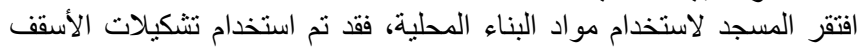

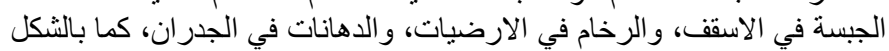

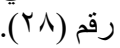

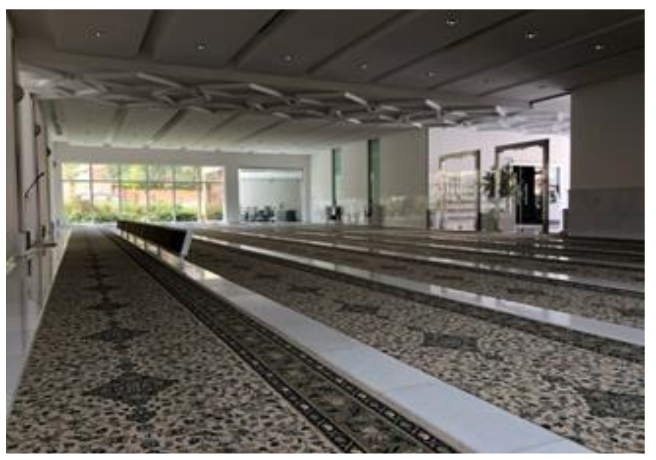

شكل رقم (YA ) : يوضح تشكيلات الأسقف الجبسة المستخدمة في المصلي

ث- الاعتبارات الجمالية:

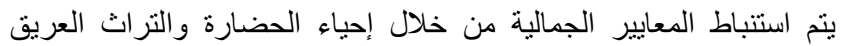

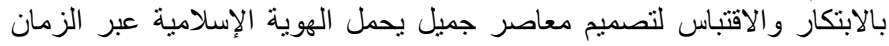

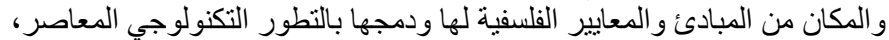

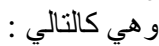
التجريي : يمثل التجريد بمسجد معمور بسيط جدا في فخامة التصميم واقل تعقيدا

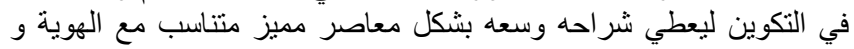

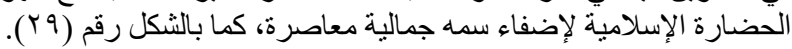

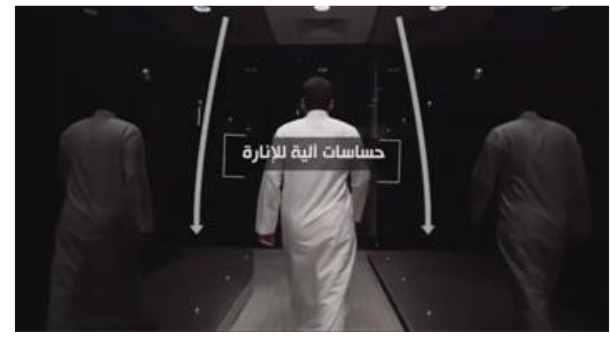

شكل رقم (Y Y ): يوضح حساسات آلية الإنارة الموجودة في الممرات

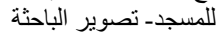

$$
\text { ل }
$$

يعتمد نظام التهوية على توزية التهيف الهواء من بين تشكيلات الأسقق الجبسيه

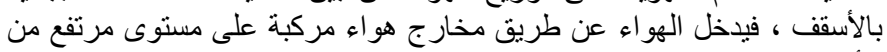

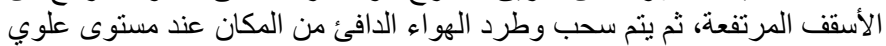

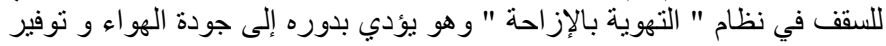

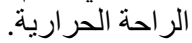

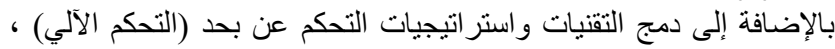

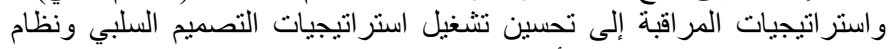

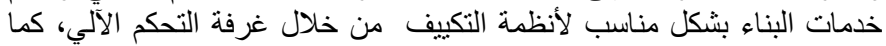

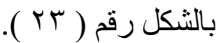

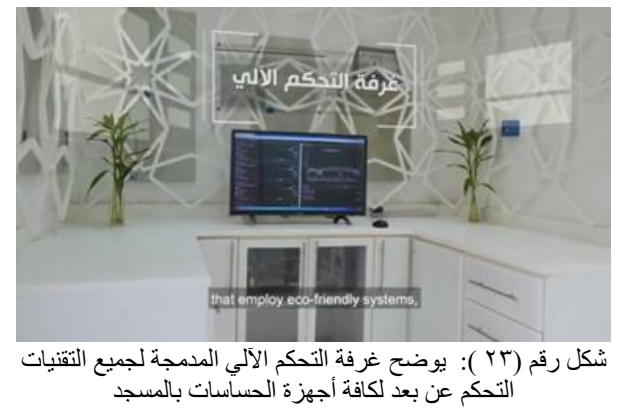

$$
\checkmark
$$

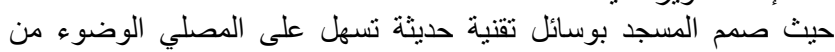

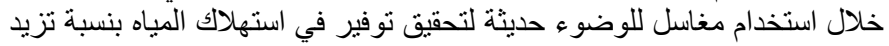

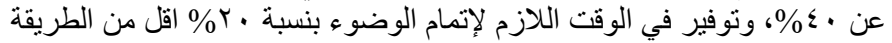

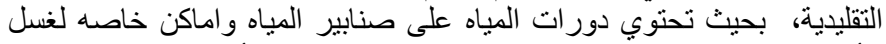

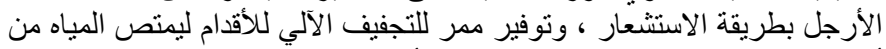

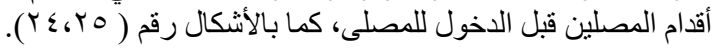

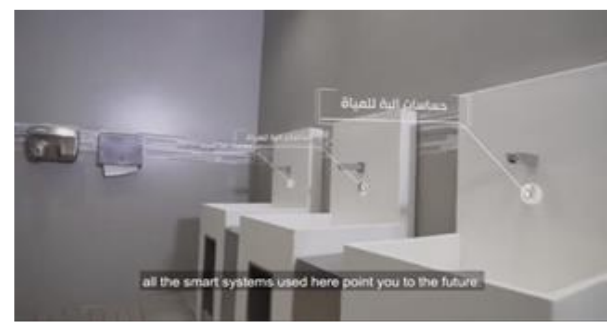

شكل رقم (؟Y ): يوضح الحساسات الآلية لمغاسل الوضوء بدورات

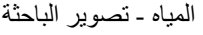

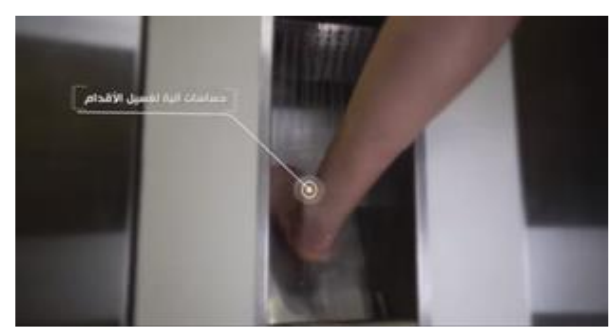

شكل رقم (Y0) ) يوضح الحساسات الآلية لغسيل الأقدام بدورات المياه-

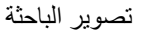


الاستمرارية : تم الحفاظ على تعبير الاستمرارية في الحفاظ على قيمة الموروث

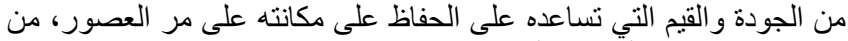
خلال : وسائل الأمن والأمان ذات اتلات التكنولوجية عالية التقنية للمعالجات

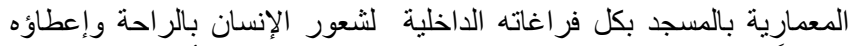

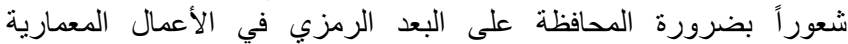

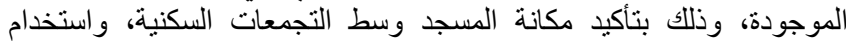

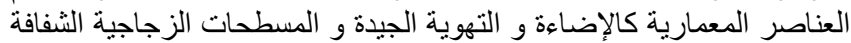

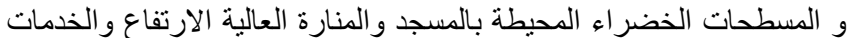

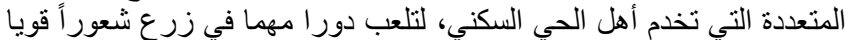

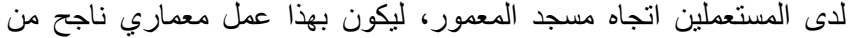
ناحية: الوظيفة، و المتانة و الجمال، وليكون بمثابة الرمز في الفر اغني ولئ وليس مجرد

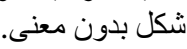

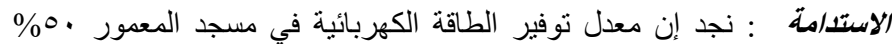

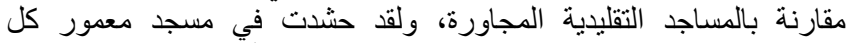
التفاصيل والتقنيات الحديثة التي تحقق استخدام الأنظمة الصديقة البيئة:

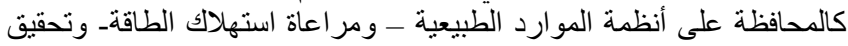

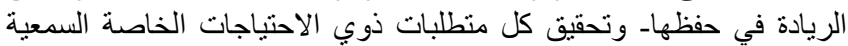

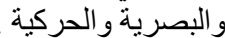

و المسجد مزود بشاشات تقنية عالية توضع فيها فوراتها مواعيد الصلاة والأذكار

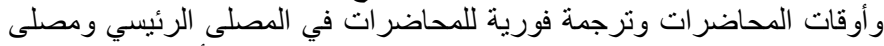

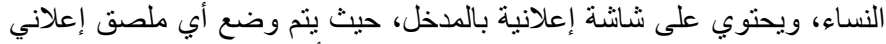

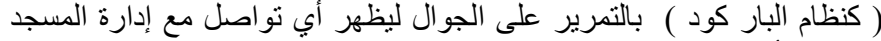

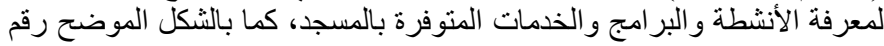

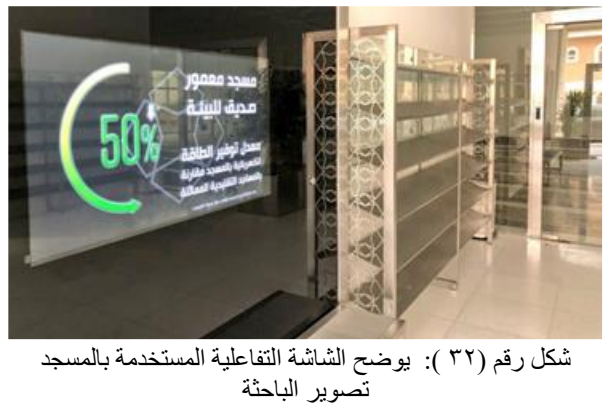

تساهم الطاقة الشمسية بنسبة 9\% من إجمالي الطاقة المستهلكة بالمسجد

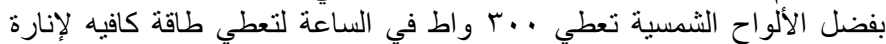

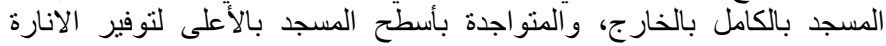

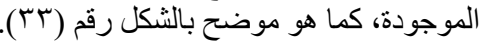

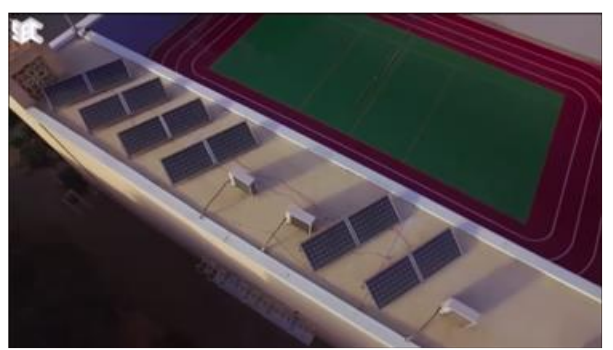

شكل رقم (rT ): يوضح الألو اح الثمسية بأعلى المسجد لإنارة المسجد بالكامل من الداخل والخارج- تصوير الباحثة

تم توفير غرفة التحكم الآلية بطريقة آلية رائعة للتحكم في الأنظمة الذكية

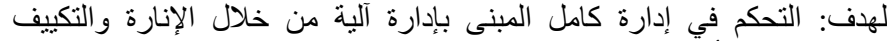

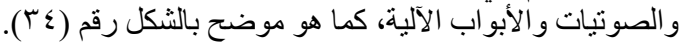

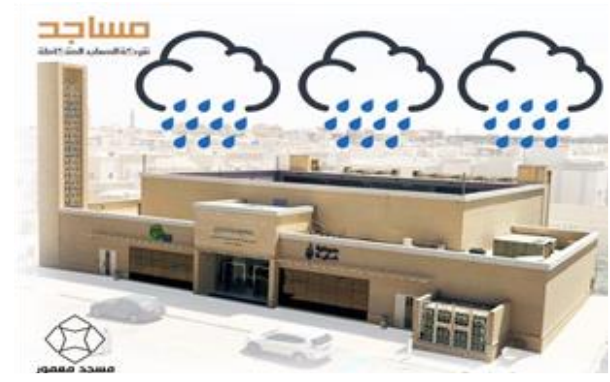

شكل رقم (9 Y ) : يوضح التكوين البسيط بشكل معاصر وممبز متناسب الاسب مع الهوية و الحضارة الاسلامية النية

فنجد تصميم الواجهة الأمامية والرئيسية للمسجد تحتوي: على المدخل

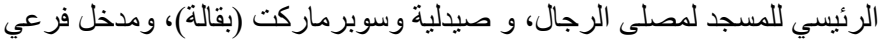

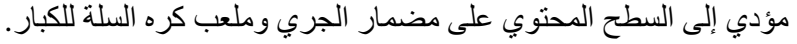

الرمزية: استخدم مسجد المعمور تعبير الرمزية في التشكيل والتصميم في

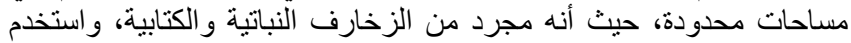

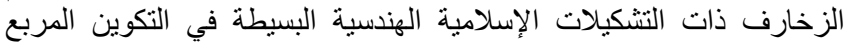

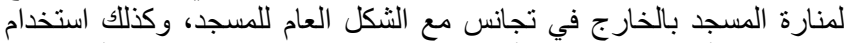

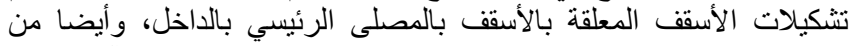

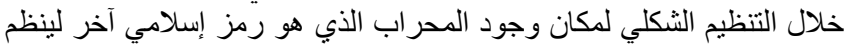

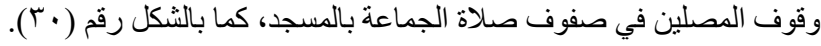

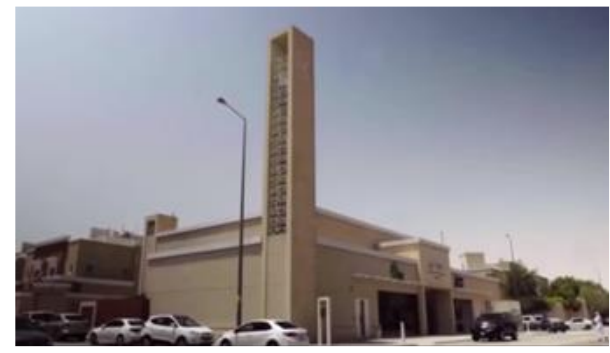

شكل رقم (• (T): يوضح التشكيلات الهندسية و الإسلامية المستخدمة في

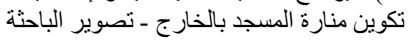

النفعية : تمثلت المنفعة والجمال بمسجد المعمور، فربط العناصر المعمارية

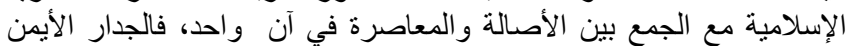

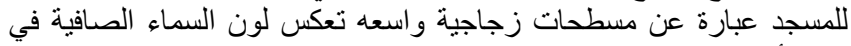

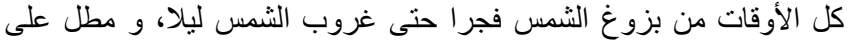

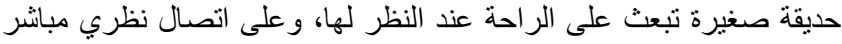

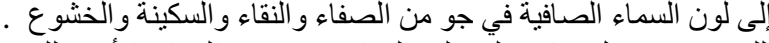

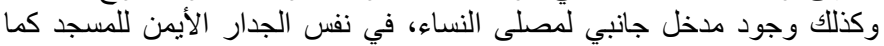

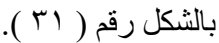

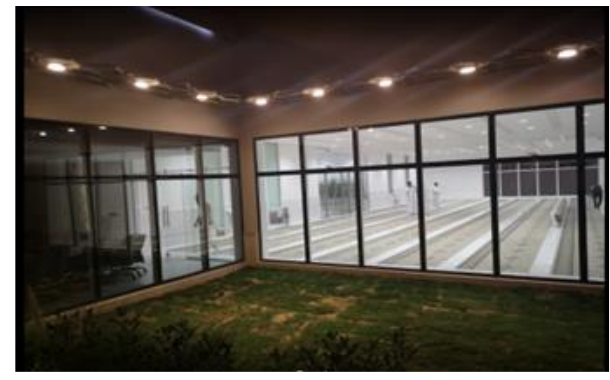

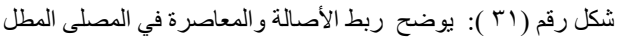
على الحيقة الخارجية للمسجد في جو من الاصد والمعاصو في والسكنية تصوير الباحثة فئة 


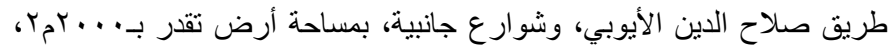

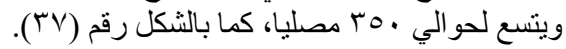

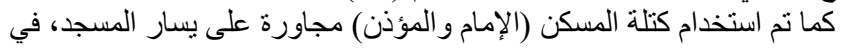
منطقة مرتفعة من الارض لتظليل الممر السفلي المنوجه للمسجد في مدخل جانبي.

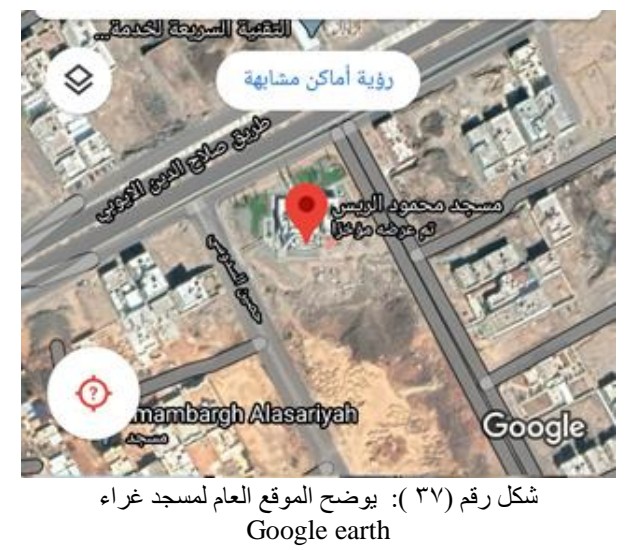

م اخبب الاختيار للمسجد: يقلل من التكاليف المالية و الهذر في التصميم التهاه

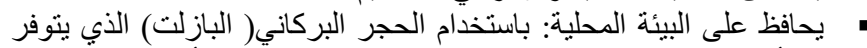

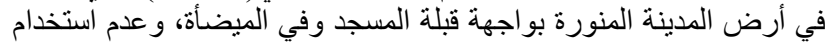

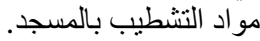
يقلل من استخدام الطاقة باستخدام الحساسات الآلية في الاضاءة و التكييف.

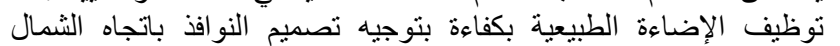

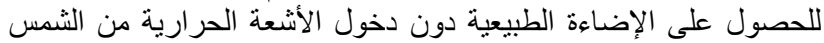

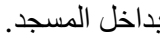

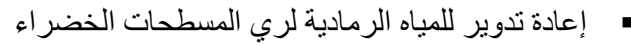

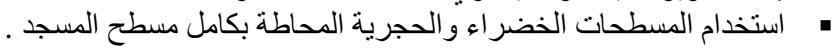

م الاعتبار ات و المتطلبات التصميمية لتقييم عمارة المساجد المعاصرة :

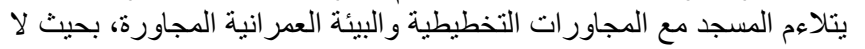

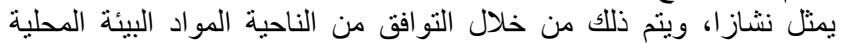

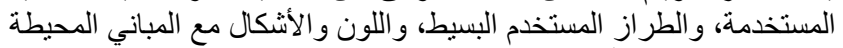

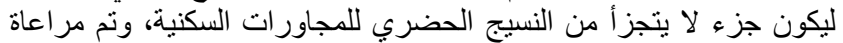

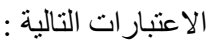

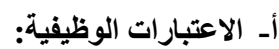

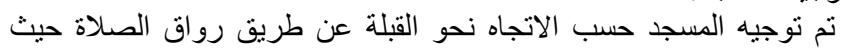

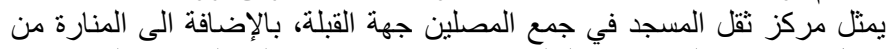

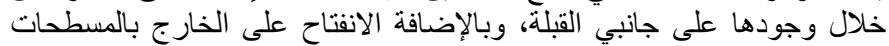

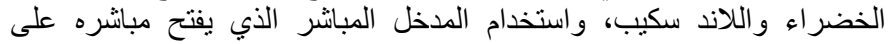

$$
\begin{aligned}
& \text { المصلى الرئيسي للمسجد. }
\end{aligned}
$$

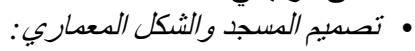

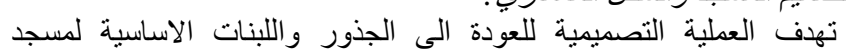

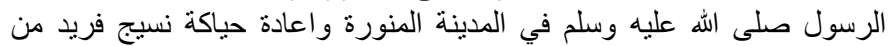

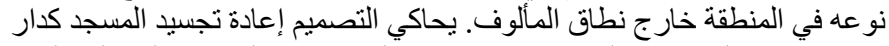

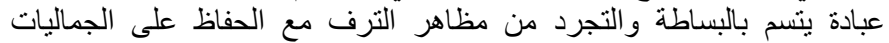

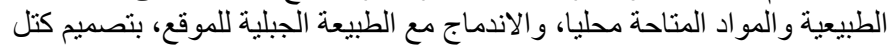

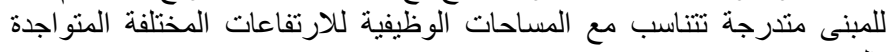

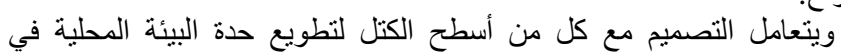

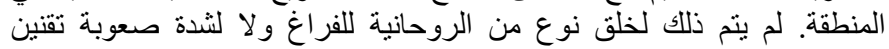

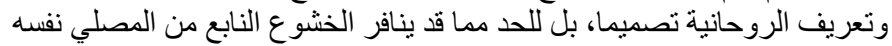

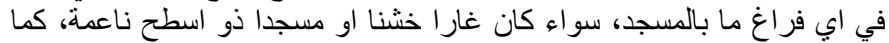

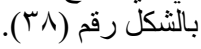

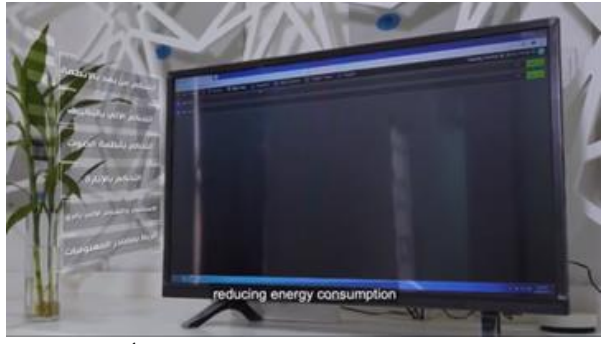

شكل رقم (؟ r) ): يوضح بر امج التحكم الآلي في الأنظمة الذكية المستخدمة بالمسجد ـ تصوير التصني

ب- مسجد الغراء ( مسجد محدود الريب )- المدينـة المنورة ـ المدلكة العربية السعوديبة

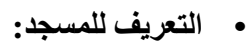

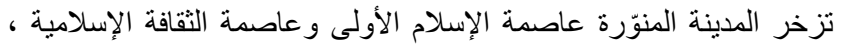

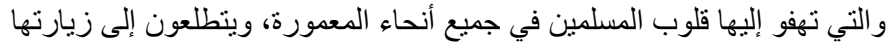

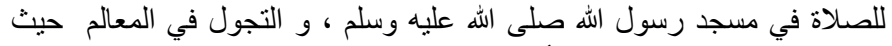

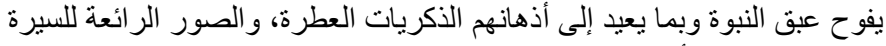

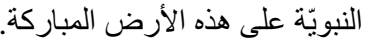

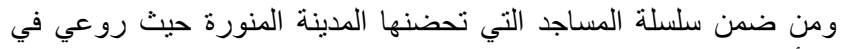

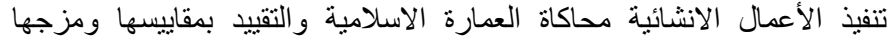

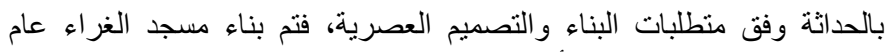

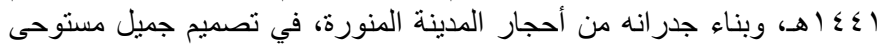

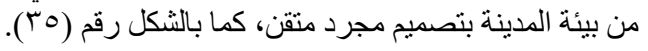

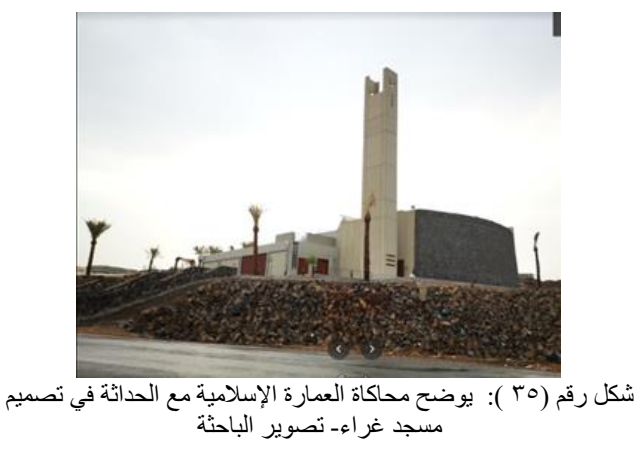

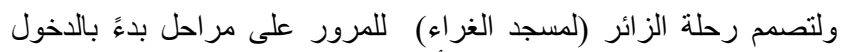

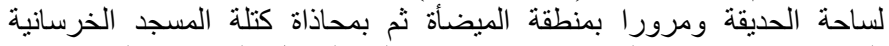

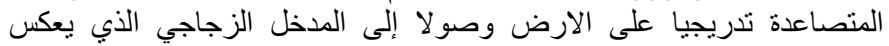

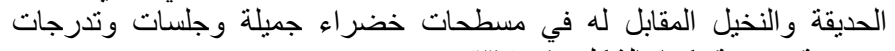

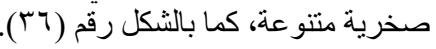

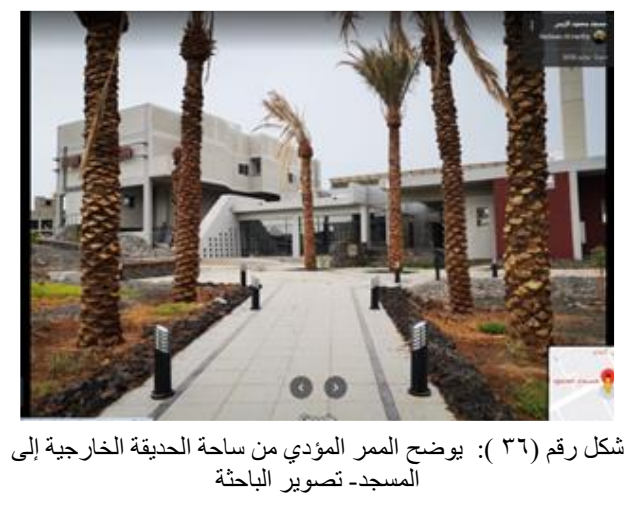

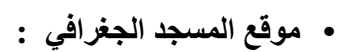

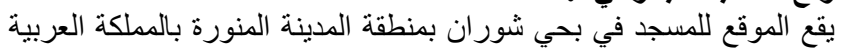

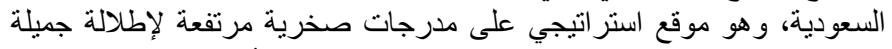

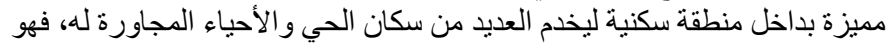

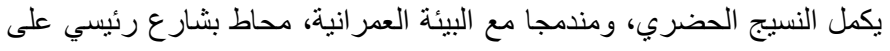




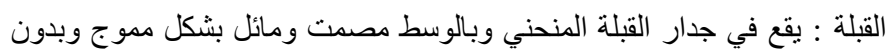

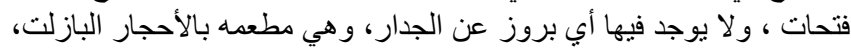

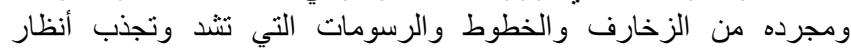

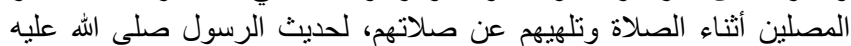
وسلم: ( لا ينبغي أنم يكون في قبلة البيت شيء يلهي المصلي )، كما بالثكل

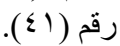

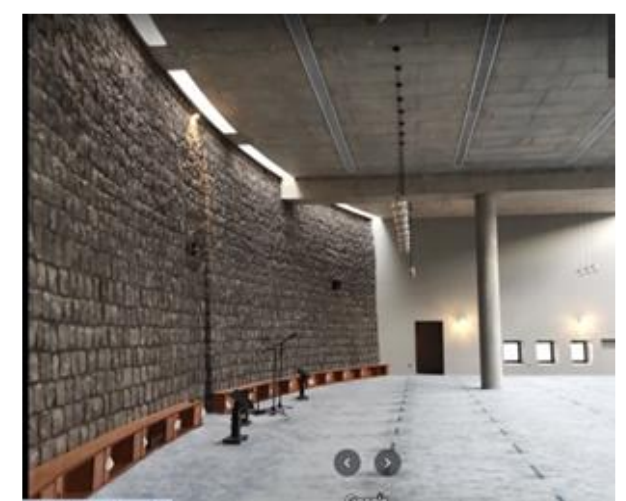

شكل رقم (1 ) ) : يوضح جدار القبلة المنحني المصدت والمموج للخارج بدون فتحات ـ تصوير آلباحثة المنة

المنبر : لا يوجد منبر بالمسجد.

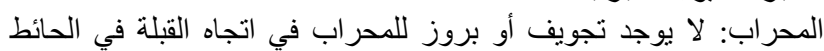

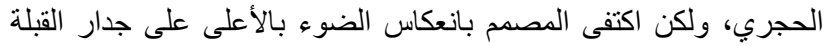

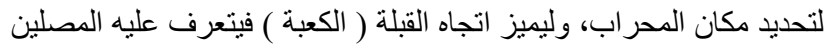

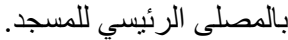

\section{|}

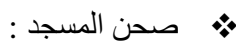

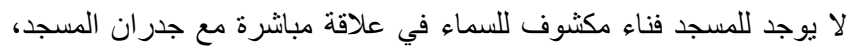

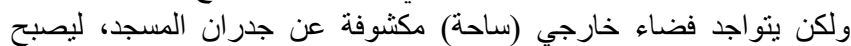

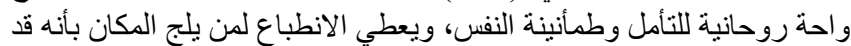

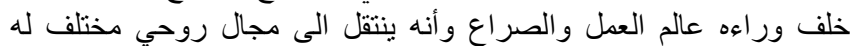

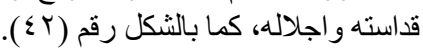

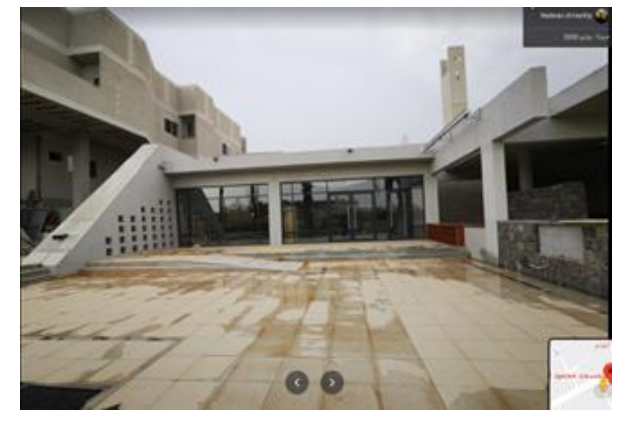

شكل رقم (r ع ): يوضح الساحة المكثوفة خارج جدران المسجد تصوير الباحثة

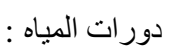

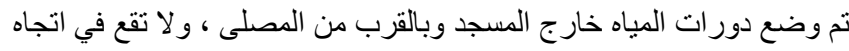

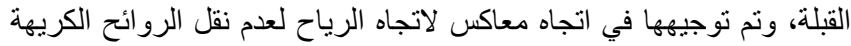

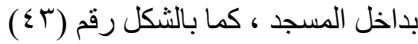

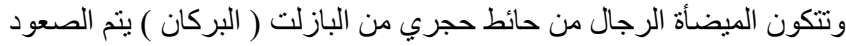

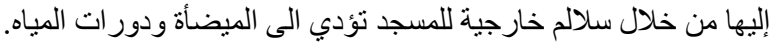

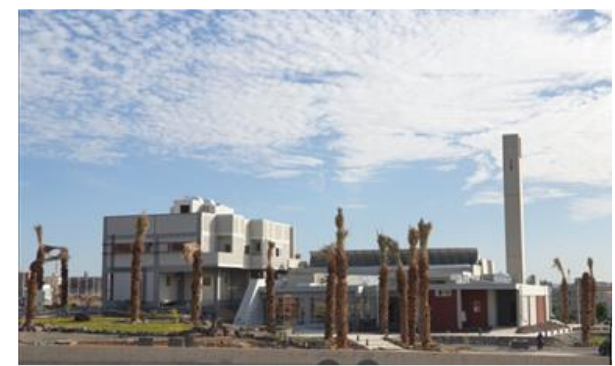

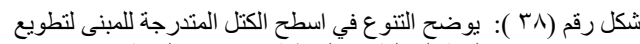

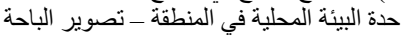

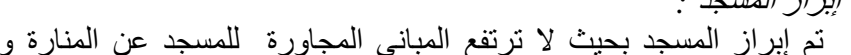

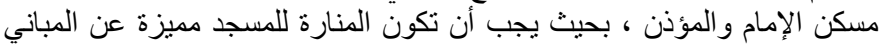

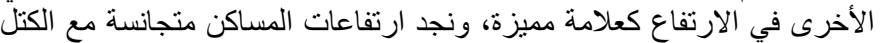

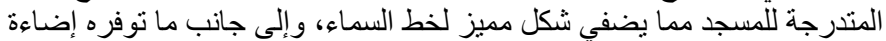
مناسبة وتظليل، بحيث برتبط المسجد مع النسيج العمر اني بالحي السكني المنو اجد النداء فيه، وبهذا يحقق المسجد الغرض الذي أنثأ من أجله.

$$
\begin{aligned}
& \text { • مكونات الدسجد : } \\
& \text { | عناصر رئيسية : ويشمل التالي: } \\
& \text { ل المصلى الرئيسي: }
\end{aligned}
$$

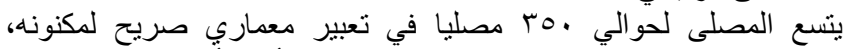

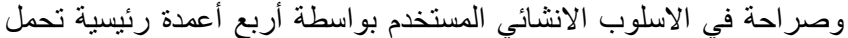
السقف الخرساني والجدران الخرسانية للمصلى الرئيسي، كما بالثكل رقي الثمل

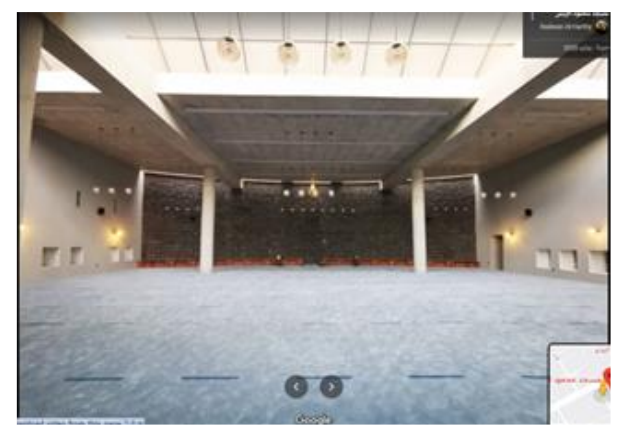

شكل رقم (Y ) ): يوضح المصلي الرئيسي للمسجد ليستو عب . م مصلي

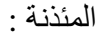

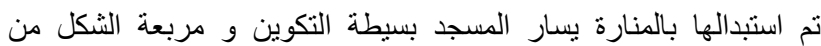

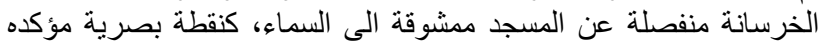

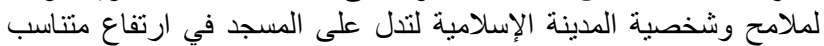
طرديا مع ارتفاع الأبنية المحيطة بها، كما بالثكل رقم (•؛ ).

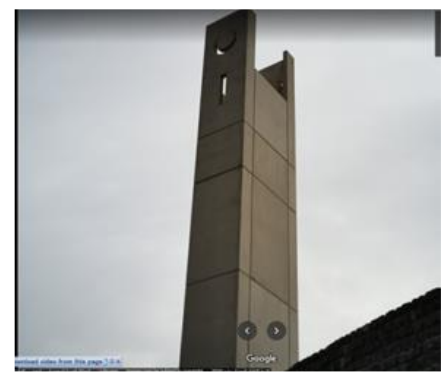

شكل رقم (•؛ ) : يوضح المنارة المصمتة بسيطة التكوين المستخدمة

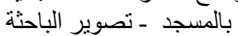




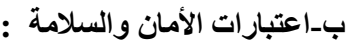

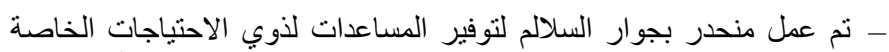
ولكراسي كبار السن بمداخل المسجد، و بالفضاءات الخارجية، كما بالأشكال رقم لألمات . ( $\{7, \leqslant \vee)$

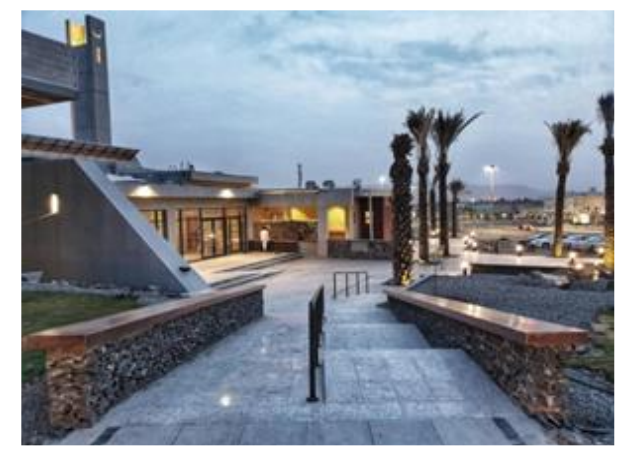

شكل رقم (7 ؛ ): يوضح الفضاءات الخارجية المستخدمة بالمسجد تصوير الباحثة

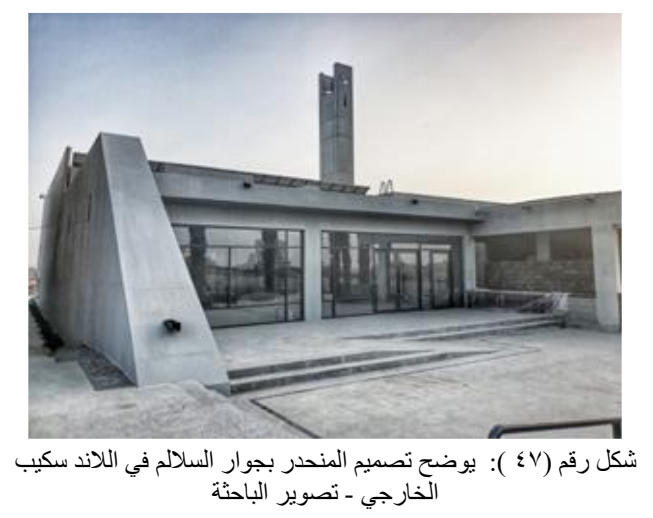

- - تم توفير أماكن مواقف السيارات ومواقف عربيات لذوي الاحتياجات الخاصة محاطه بكامل المسجد، كما بالثكل رقم (^) ـ).

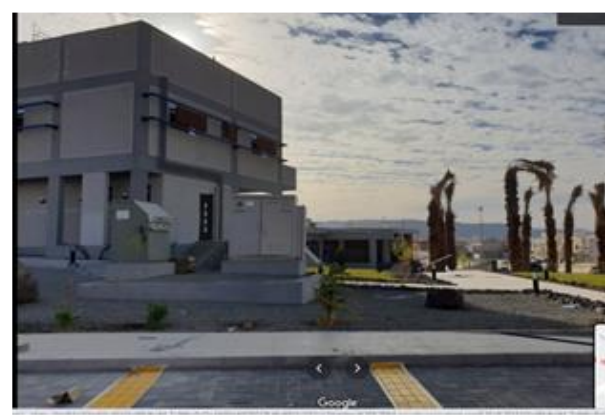

شكل رقم (1ء ) : يوضح أماكن مو اقف السيار ات و عربيات ذوي الاحتياجات الخاصة محاطة بكامل المسجد بالخار ج- تصوير الباحثة

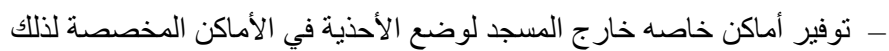

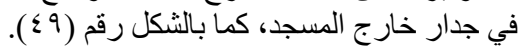

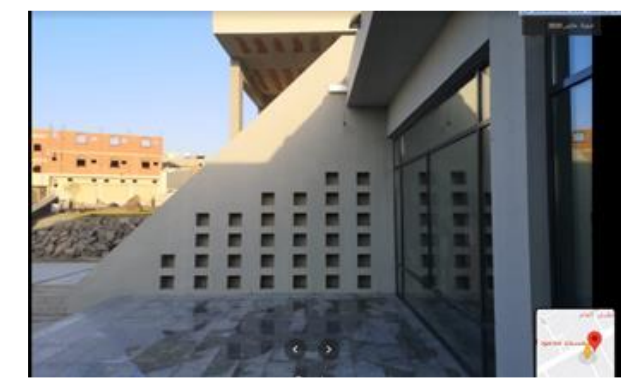

شكل رقم (9 ؛ ): يوضح أماكن يخصية لوضع الأحنية خارج المسجد

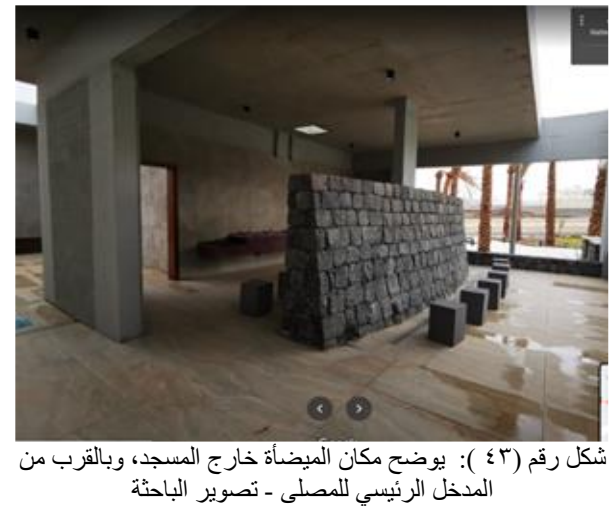

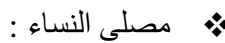

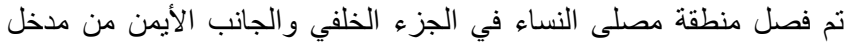

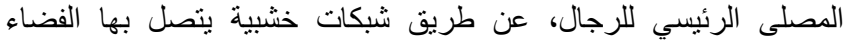

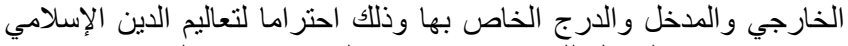

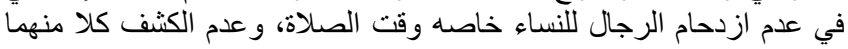

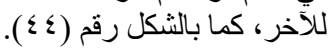

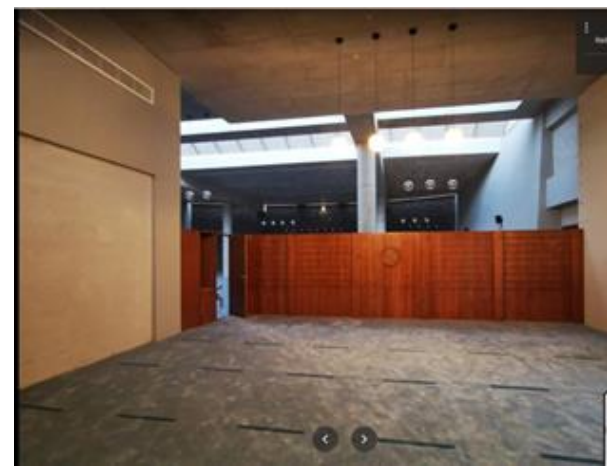

ثكل رقم (؟ ؛ ): يوضح الجزء الخلفي لمصلى النساء بالمسجد تصوير الباحثة

\section{4 | عناصر إضافية : ويشمل التالي:}

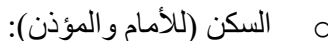

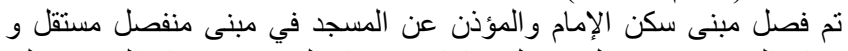

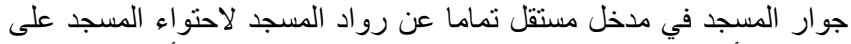

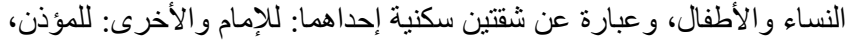

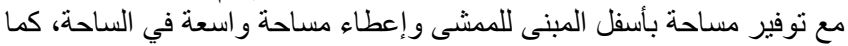

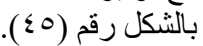

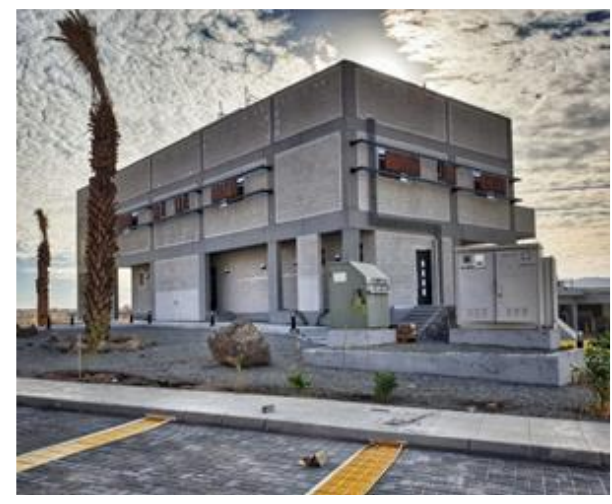

شكل رقم (0ء ): يوضح مبنى سكن الإمام المنفصل عن مبنى المسجد و المجاور لله ـ تصوير الباحثة المنام المني 


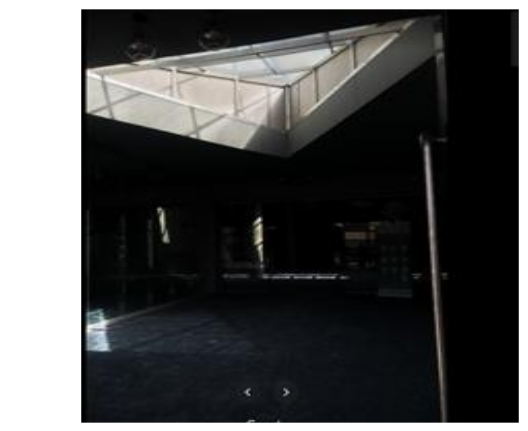

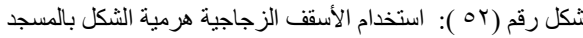

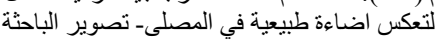

• استخدام الاضاءة الصناعية في أماكن محددة

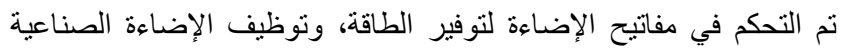
أثناء الليل لتكون للقر اءة في أماكن محدودة.

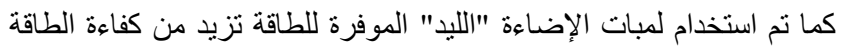
الكهربائية وقوة أنظمتها على مدى السنوات، واستخدمت الاضاءة الصاءة الصناعية في

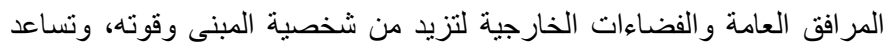

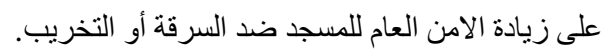

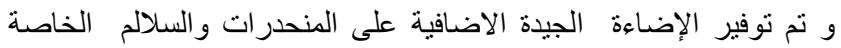

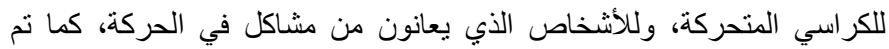

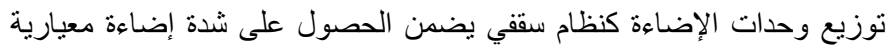

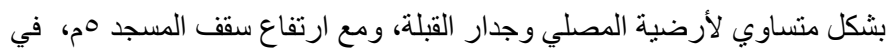

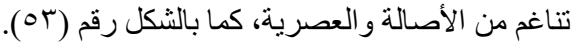

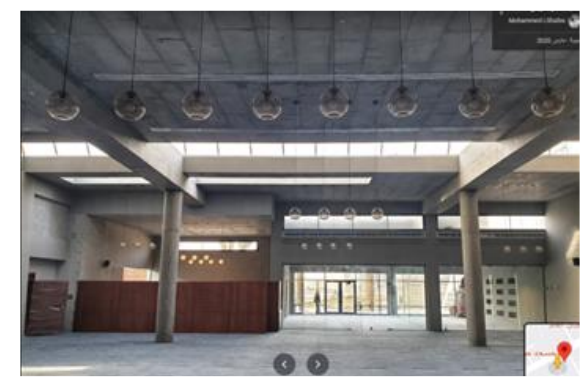

شكل رقم (ror ): يوضح توزيع وحدات الإضاءة كنظام سقفي موفر للطاقة المستخدمة المسجد- تصوير الباحثة

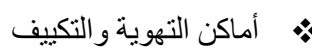
تم استعمال أنظمة التكييف ذات شبكات ومجاري توزيع الهواء بالأسقف،

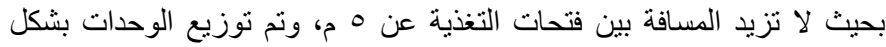

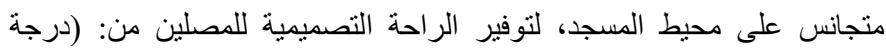
حرارة، رطوبة، تهوية، تنقية هو اء، تجديد هو اءو).

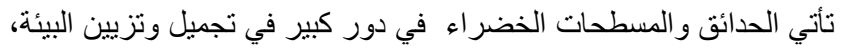

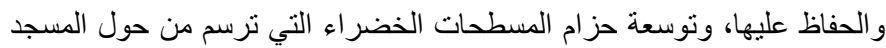

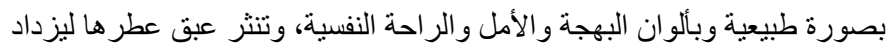

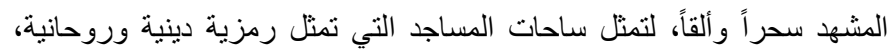

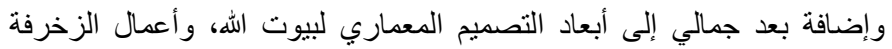

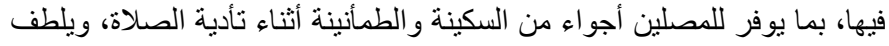

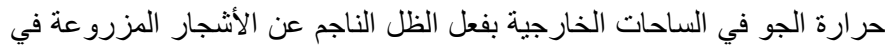

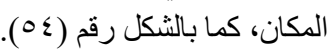

- وجود مداخل على واجهه المسجد، بالإضافة الى مخارج الطوارئ إضافية بالمسجد. - تم وضع سندات الظهر بالصفوف الأولى للمصلين التي تطول فترة جلوس المصليين فيها، حيث يأتون مبكرا ويمشون متأخرين لانتظار خلاء مسارا بالصفوف التالية.

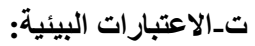

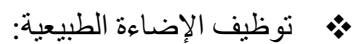

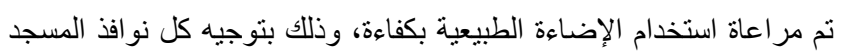

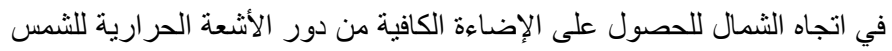
لتوفير استههلاك الطاقة بالمسجد. وكذلك تم توجيه النوافذ الصغيرة في اتجاه الثرق والغرب لإتاحة دخول

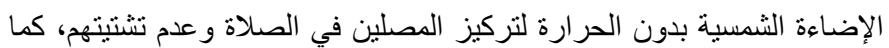

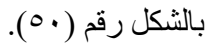

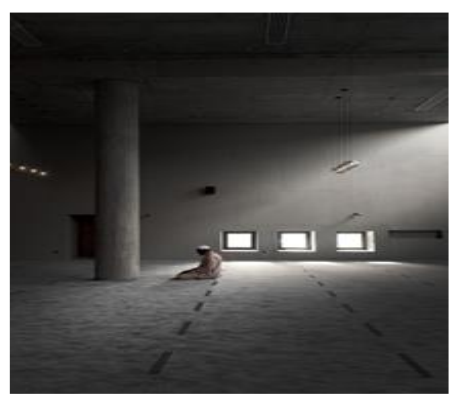

شكل رقم (.0 ): يوضح النو افذ الصغيرة المستخدمة في اتجاه الثرق

و إتاحة وجود الإضـاءة المباشرة القوية في جدار القبلة وذلك لإعطاء رمزية لاتجاه

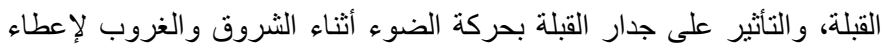

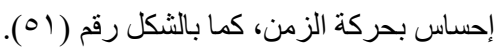

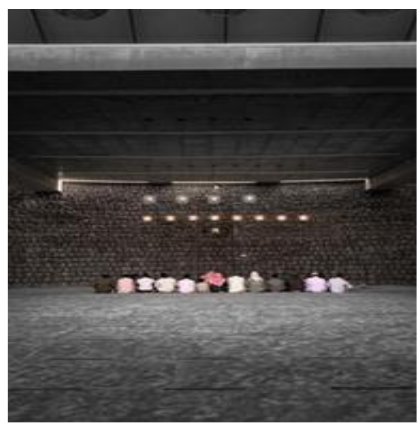

شكل رقم ( (10 ): يوضح الإضاءة القوية المستخدمة بجدار قبلة المسجد تصوير الباحثة الإنة

تم تصميم فتحة زجاجية هرمية الشكل بأسقف المصلى الرئيسي ( سكاي

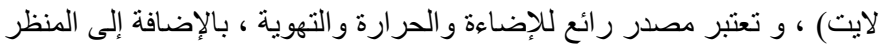

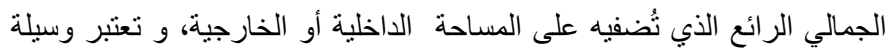

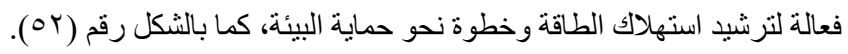


كما تم استخدام الحجر البركاني ( البازلت ) الذي يتوفر في البيئة في الميضأة

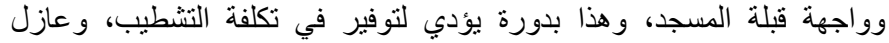

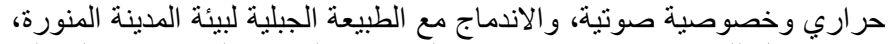

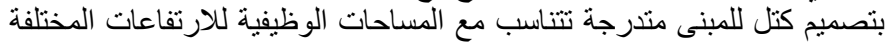
بالموقع ، كما موضح بالثكل رقم (ov).

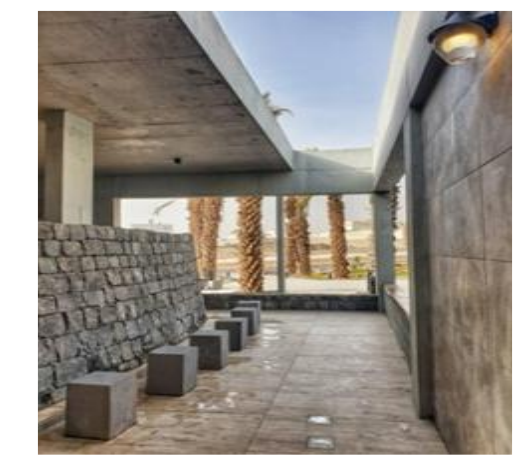

شكل رقم (OV ) : يوضح الحجر البركاني المستخدم في الميضأة تصوير الباحثية

ث_الاعتبارات الجمالية: - مالية

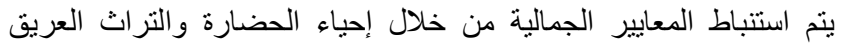

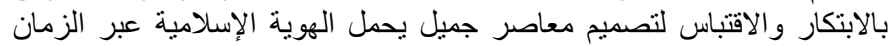

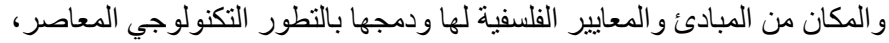
وهي كالتالي : والمن المبان

التجريا :يقايض التصميم التجرد من الزخارف في العناصر الداخلية أو الخارجية،

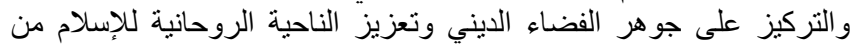

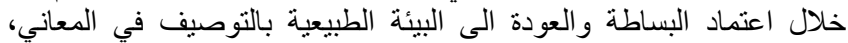

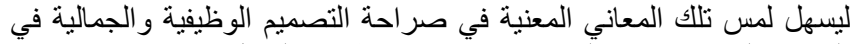

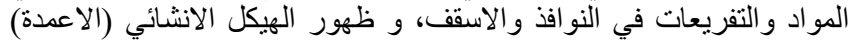

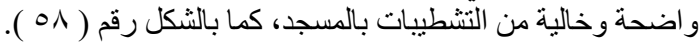

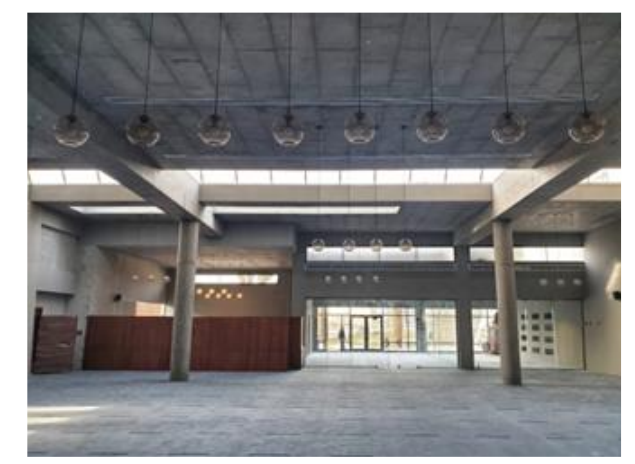

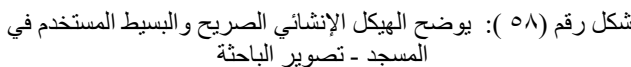

الرمزية :يتصدر التصميم للمسجد في كتله وصورة رمزية، وتعابير الجمال

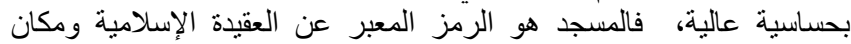

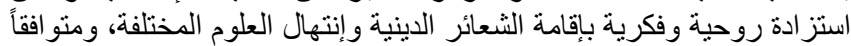

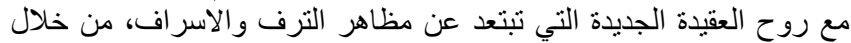

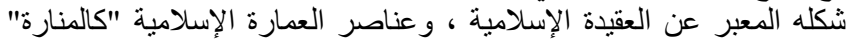

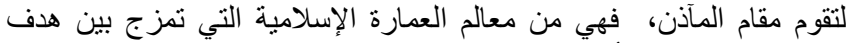

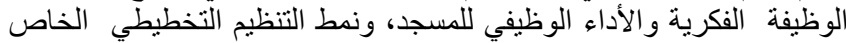

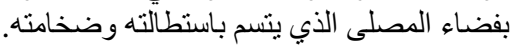

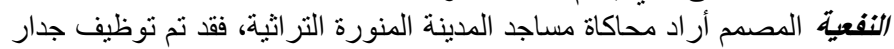

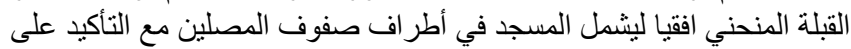
وسطية الامام واستخدام حجر الحرة البركاني المحلي في بنائه باعتباره أحد المد الئل

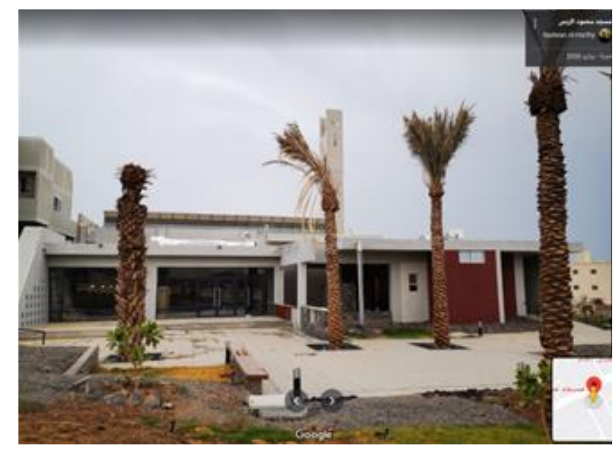

شكل رقم (ع ه ): يوضح الحدائق الموز عة حول المسجد بصورة طبيعية و ألوان مبهجه ـ تصوير الباحثة التوزئة

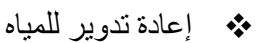

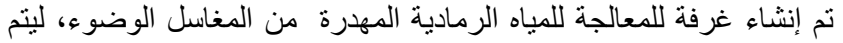
إعادة تدوير ها بعد تلقيتها إلى صناديق الطردة، للاستفادة منها في ري الرمادي الحدائق لئق

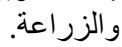
تم الاستفادة من مياه الإمطار بعمل مواسير صرف الأمطار من الأسطح

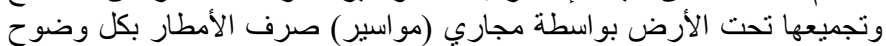

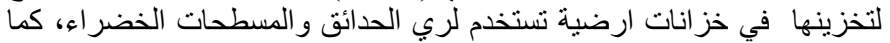

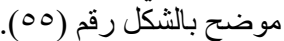

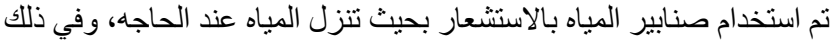

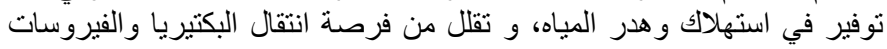
بين المصليين.

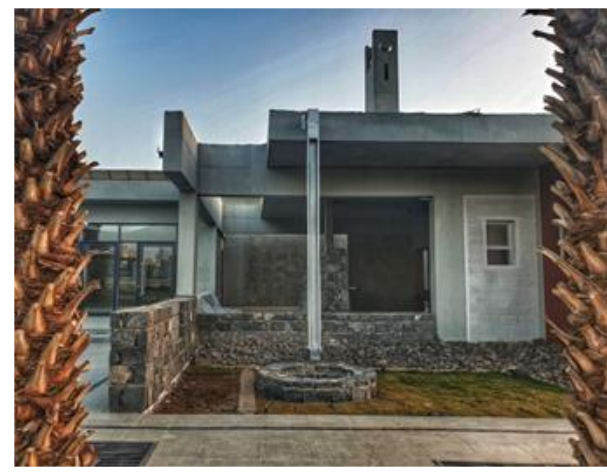

شكل رقم (00 ): يوضح مو اسير صرف مياه الأمطار المؤدية إلى الى القات

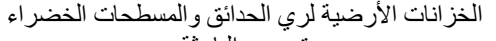

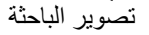

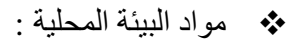
تم استخدام المواد المحلية و المتاحة من بيئة المدينة المنورة،ة، و عدم استخدام

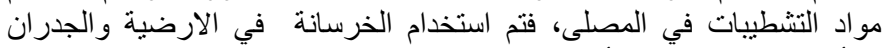

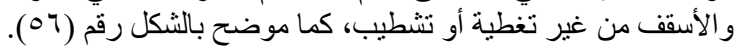

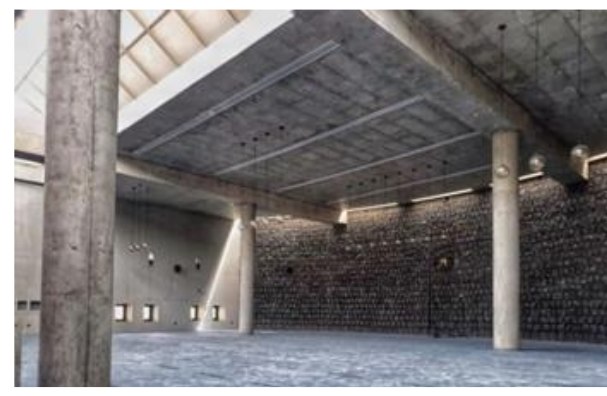

شكل رقم (07 ): يوضح عدم استخدام مو اد التثطيبات بالمسجد تصوير الباحثة 
- كما أن المسجد يقع في منطقة المناخ الحار الرطب يتم الاستفادة من مياه الامطار والخصائص الثمسية في أنشطة المسجد لتوظيف التيف المياه في اعمال

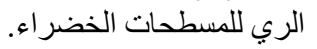

\section{VI لدراسة تطبيقية ( استبيان ):}

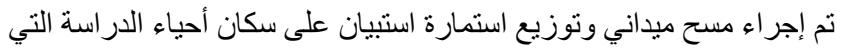

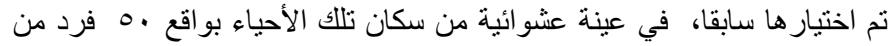

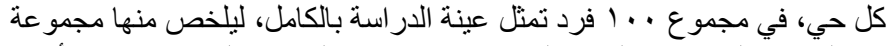

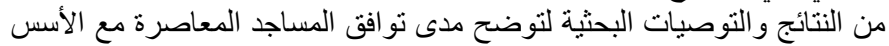

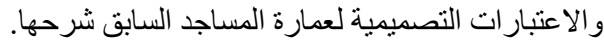

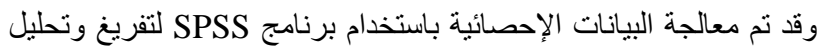

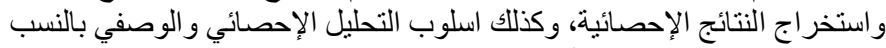

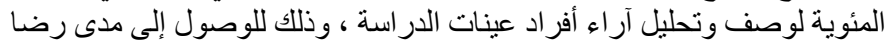

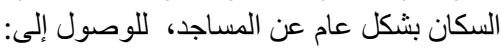

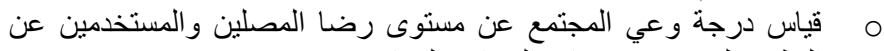

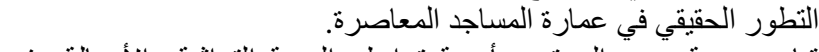

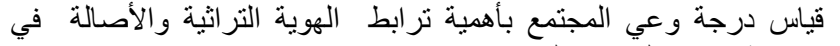

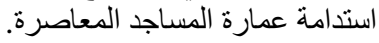

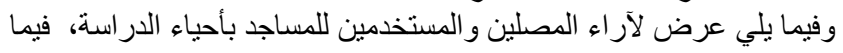

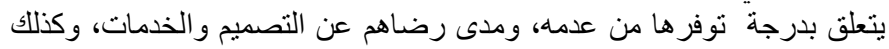

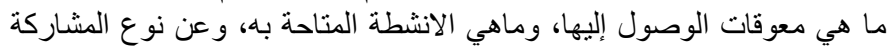

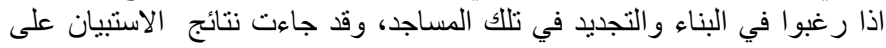

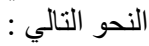

أـ هل يتوفر مسجد في الحي ( المنطقة ) الأي تسكن فيه ؟* مة

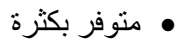

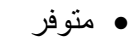

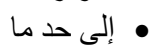

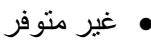

توضح اجابات المستخدمين عن مدى " توفر المساجد بأحياء الدراسة الذين يسكنون فيها "، كانت الإجابة أن:

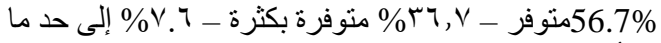
أي أن: بنسبة كبيرة تتمنل في

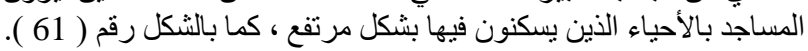

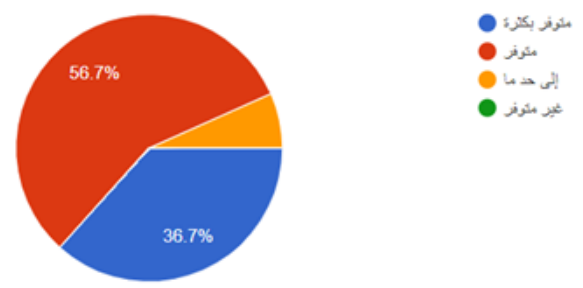

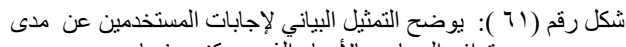
تو افر المساجد بالأحياء الذين يسكنون فيها لإبات الذيات

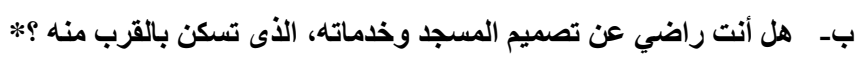

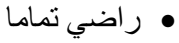
• • • • • إلى حد ما • غير راضي مال

توضح اجابات المستخدمين عن مدى " رضاهم عن تصميم وخدمات المسجد

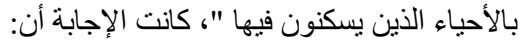

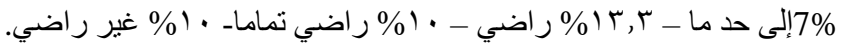

عناصر البناء المعروفة والمشهورة في المدينة المنورة وتوفره في بيئتها،

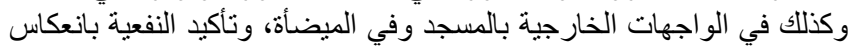

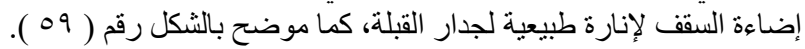

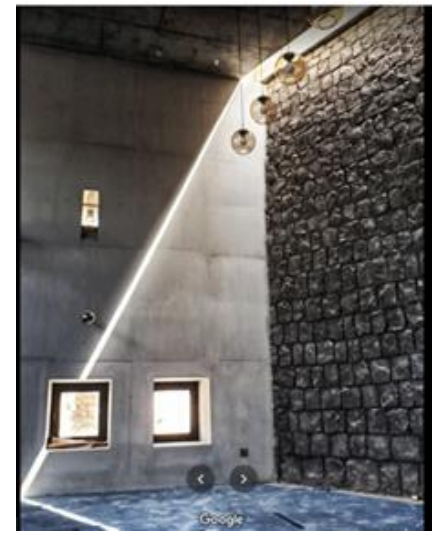

شكل رقم (9 ه ): يوضح انعكاس اضاءة السقف لإنارة طبيعية لجدار القبلة المستخدم لحجر البازلتـ تصوير الباحثة البنة

الاستصرارية : تأتي مفهوم الاستمرارية من خلال علاقة فضاء المصلى بيقية

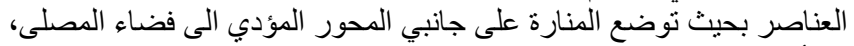

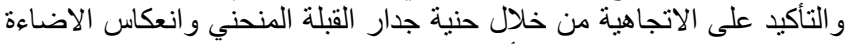

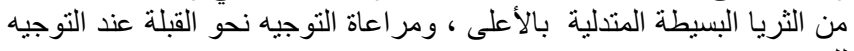

للمسجد.

بالإضافة الى فصل فضاء المصلى الرئيسي ومناطق الوضوء عن عن بقية

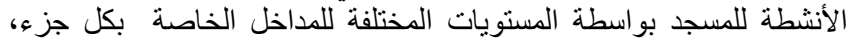

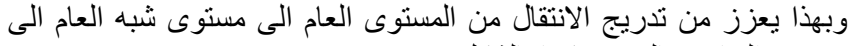

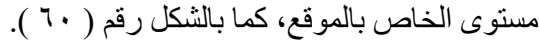

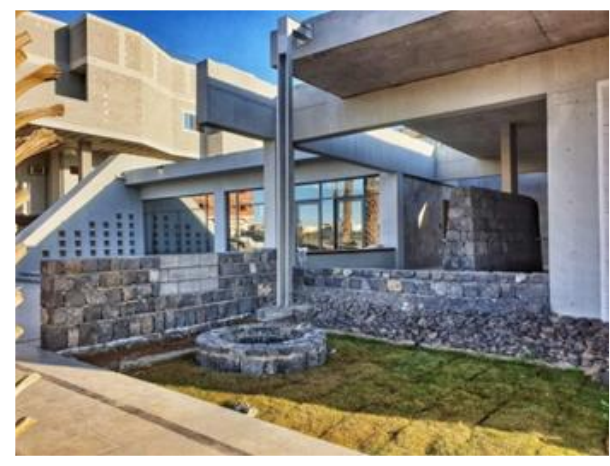

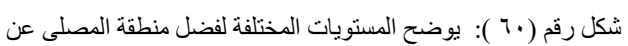
منطقة الوضوء و وأنشطة المسجد المختلفةـ تصوير الباحثة

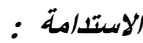

- احتوت الجدران لقاعة الصلاة على حلول معمارية مستدامة تحقق العزل

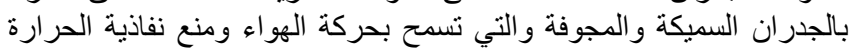

لقاعة الصلاة.

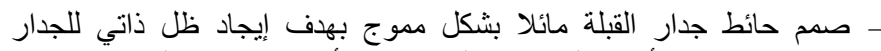
وتوزيع تركيز الأشعة الثمسية على مساحة أكبر بدلا من من المساحة مدية محدة كالمعالجة المناخية نفسها التي استخدمها المئمي المصدم.

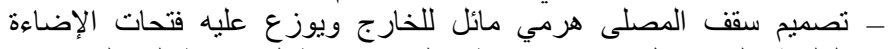

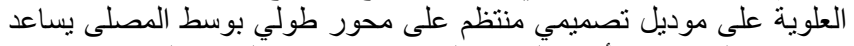

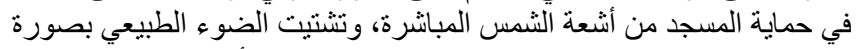

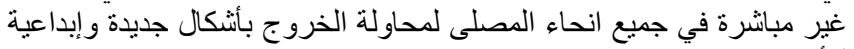
للأسقف. ـ كما يتم اعادة تدوير مياه الوضوء لـواء (المياه الرمادية) بمحطة تنقية في المسجد

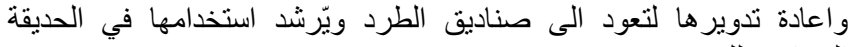

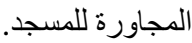


ج- ما هي معوقات الوصول للمسجد في منطقتك؟؟

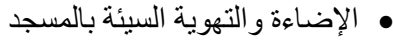
• • • • بورات المياه غير نظيفة

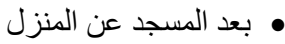

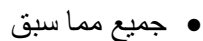
• ل اتوجد معوقات الوصول

توضح اجابات المستخدمين عن معوقات الوصول والذهاب للمساجد بأحياء

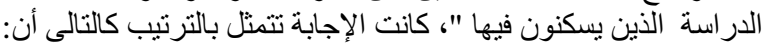

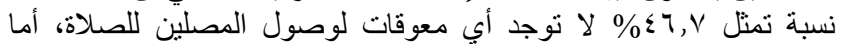

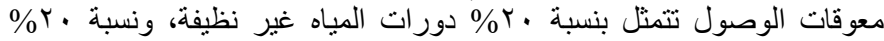

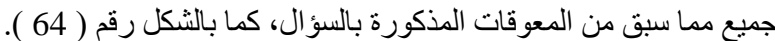

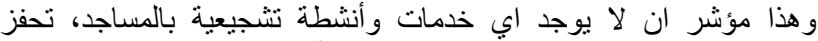

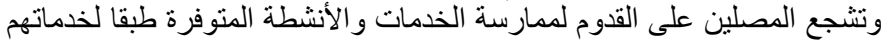
و احتياجاهم الهمبن

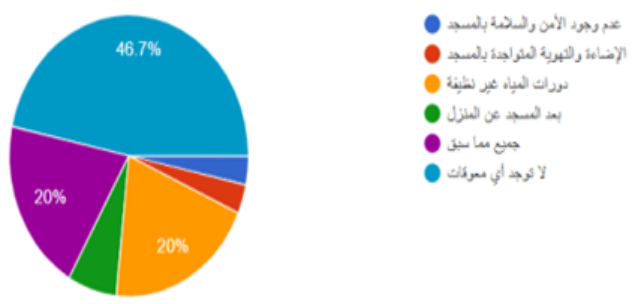

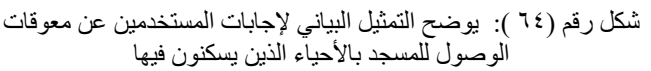

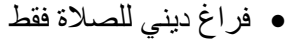
• فراغ تعليمي لتعليم الدروس و القرآن

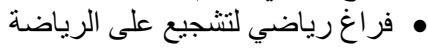

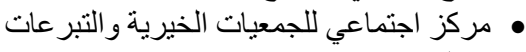

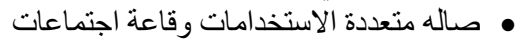
• فر اغ لمر اسم إعلان الزواج والخات واحتفالات الأعياد • • حديقة وروضة لتعليم الأطفال

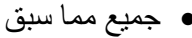

توضح اجابات المستخدمين عن الكيان والأنشطة بأحياء الدراسة الذين

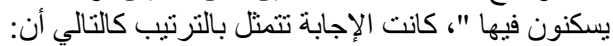

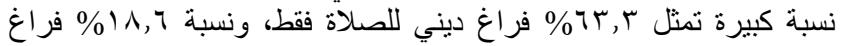

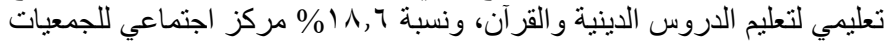

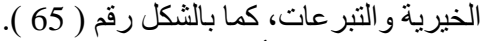

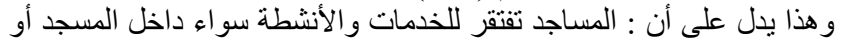

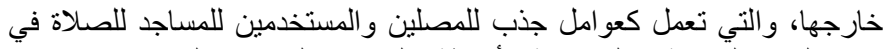

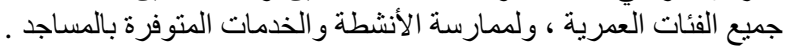

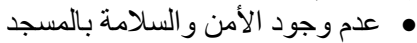

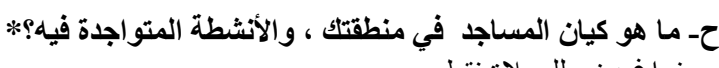

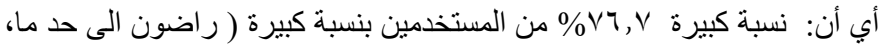

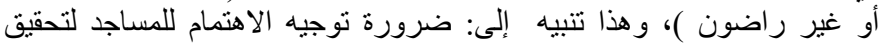

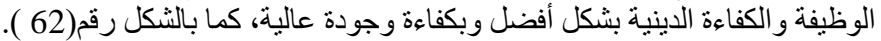
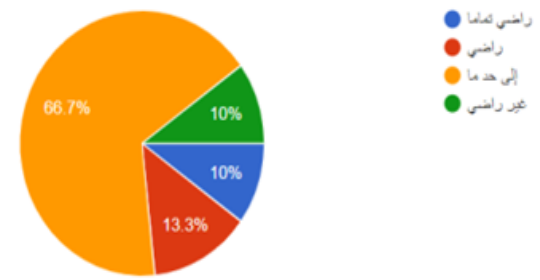

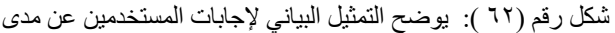

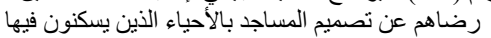

تــ إذا كانت إجابتك ( راضي تمامـا أو راضي ) عن تصميم المسجد وخدماته،

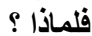

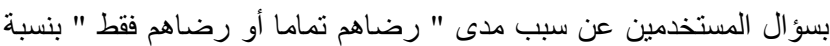

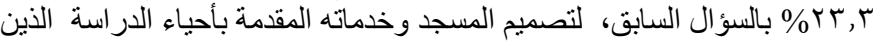

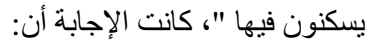
- تصميم المسجد يجمع بين الطابع الإسلامي وانئ والحديث. - - منظهر العام و اتساع المسجدئ. - مثوفر فيه الخدمات واعل المساحات الكافية لأداء الفرائض للمصلين والنشاطات الدينية الاجتماعية لسكان المنطقة

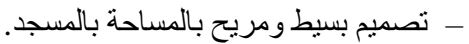
- مساحته كافية وتصمبمه مقبول. - مكان المسجد يتوسط المجامع السكنية. - التصميم الجيد ، نظافة المبنى ، استغلانل المبلد المساحة بطريقة جيدة ، دمج الطراز الاسلامي بطريقة حديثة.

ثــ إذا كاتت إجابتك ( إلى حد ما ، أو غير راضي )، ما الذي تفقده المساجد في منطقتك من خدمات ؟ o ساحات ومنطقة خضر اءت مناء o 0 o O أنشطة تعليميه o o o o

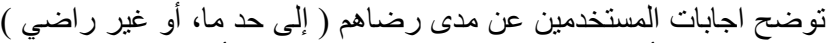

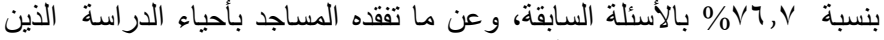
يسكنون فيها "، كانت الإجابة أن:

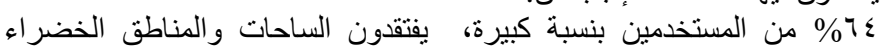

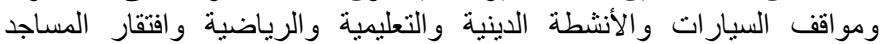

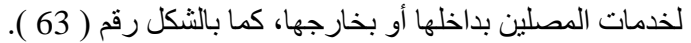
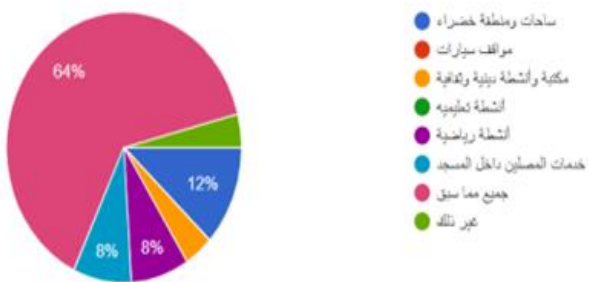

شكل رقم (70 ) : يوضح التمثيل البياني لإجابات المستخدمين عن كيان المساجد بالأحياء الذين يسكنون فيها، والأنشطة المنو اجدة فيها
شكل رقم (rآT ): يوضح التمثيل البياني لإجابات المستخدمين بنسبة

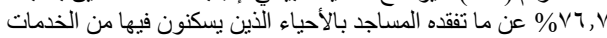


ر-هل تم أخذ رأيك ( قبل أن يينوا أو قبل أن يجدوا المسجد ) في منطقتك؟

o 0 V 0

لاؤال المستخدمين عن رغبتهم في إبداء آرائهم سواء في البناء أو التجديد

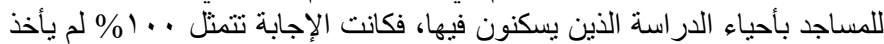

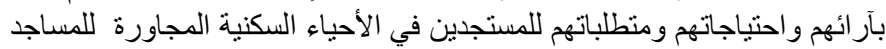
المنشأة في الوضع الحالي. ، كما بالثكل رقم ( 67 ).

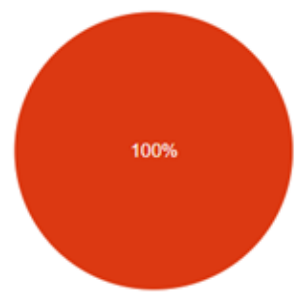

$$
\text { ن. }
$$

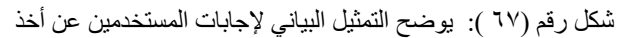

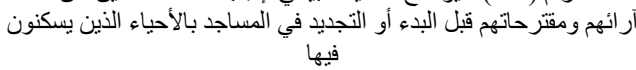

ز-إذا أجبت ( نعم )، تم أخذ رأيك * قبل أن يبنوا أو قبل أن يجدوا المسجد

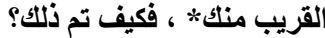
بناء على نتيجة السؤال السابق: بأنه لم يتم اخذ آراء المستخدمين من قبل،

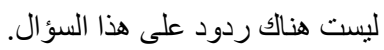

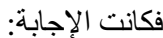

س- إذا أجبت ( لا )، لم يتم أخذ رأيك ( قبل أن يبنوا أو قبل أن يجدوا المسجد

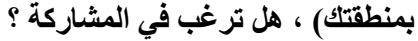

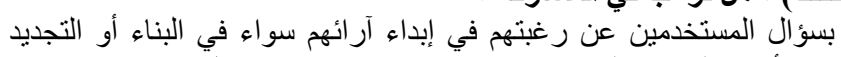

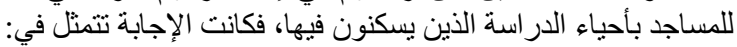

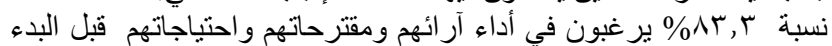

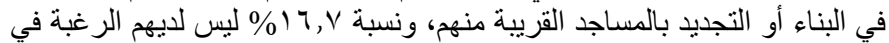

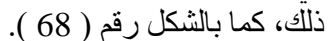

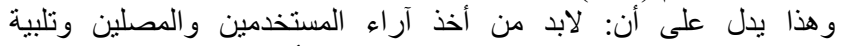

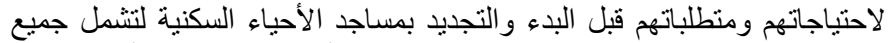

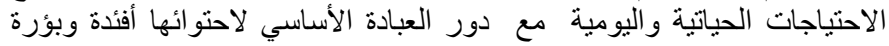

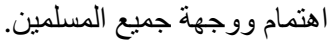

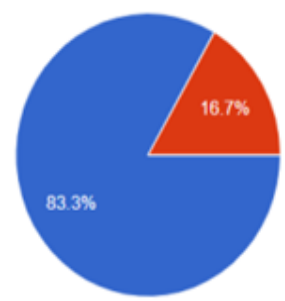

شكل رقم (1/ ) : يوضح التمثيل البياني لإجابات المستخدمين عن رغبتهم

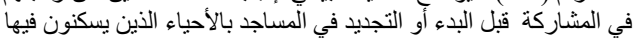

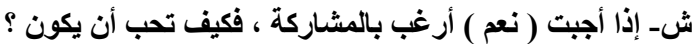

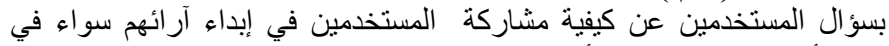

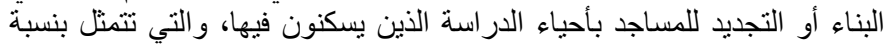

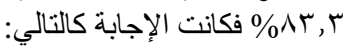

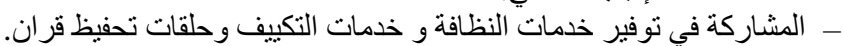
- - المشاركة في مقترحات تفيد تصميم المسجد وخدماته.

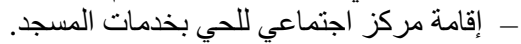

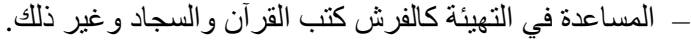
- اخذ الآراء في التصميم والأنشطة المختلفة ومعرفه العدد التقريبي لسعه المسجد

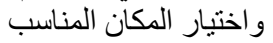

خـ هل تتشابه المسجد في منطقتك، في (( أصالة وهوية وتكوين )) مع المساجد

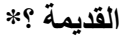
o ע 0

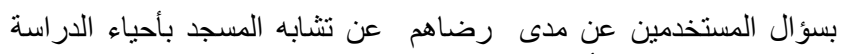
الذين بسكنون فيها ، في" أصالة وقيم وهوية وتكوين " بالمساجد القديمة، كانت

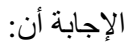

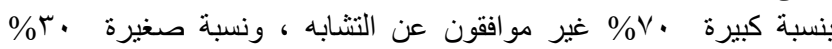
مو افقون عن التشابه، كما بالثكل رقم ( 66 ماند ). و هذا يشبر أن المساجد الحديثة فقدت ( الهوية و التراث و والأصالة والتكوين

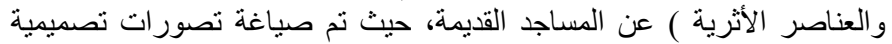

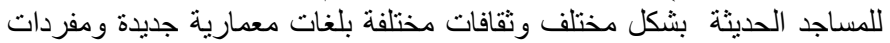

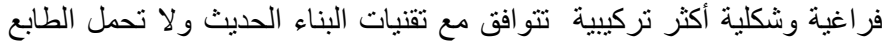

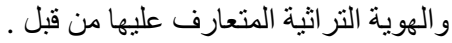
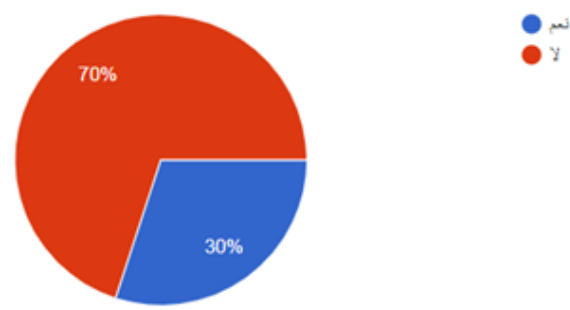

شكل رقم (T7 ) : يوضح التمثيل البياني لإجابات المستخدمين عن تشابه

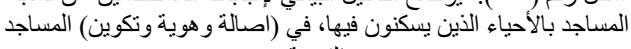
القديمة في في

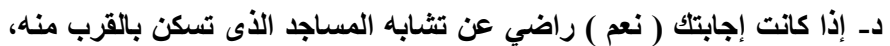

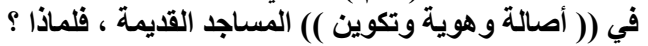

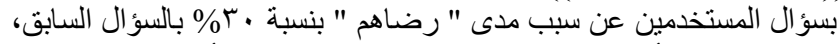

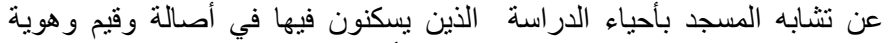
وتكوين " عن المساجد القديمة، كانت الإجابة أن:

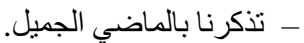

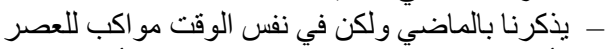

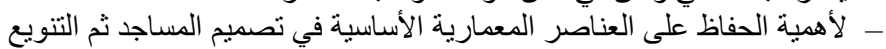
في نوع وتصميم المعالجة بصور حديثة ومتنو عة.

ذـ إذا كانت إجابتك ( لا ) ، فما شكل وتكوين المساجد الجديدة التي ترغب في تصميمها، وكيف تكون مختلفة؟ لإن

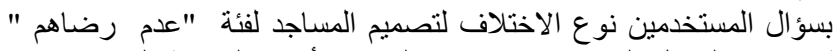

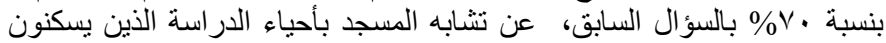
فيها في "أصلالة وقيم و هوية وتكوين " المساجد القديمة، كانت الإجابة أن:

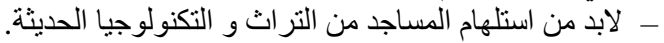

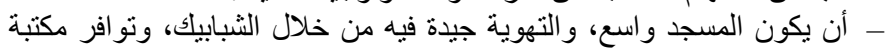
من الكتب ومكتبة إلكترونية عن طريق الحاسب، ويضم فئم انثطة اكبر و وابسط في

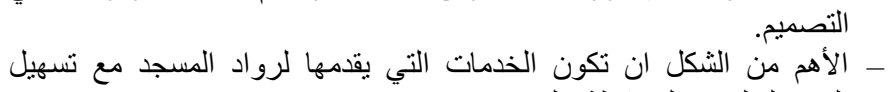

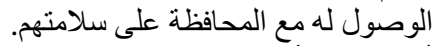
- أن تصمم الأبواب عالية الارتفاع و و واسعه، و الثبابيك كبيرة هواء طبيعي و إنارة طبيعية كما كان تستخدم بالمساجد القاعدة القديمة.

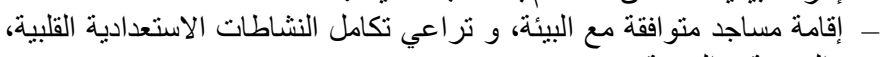

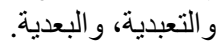
- استنباط اشكال حديثه للمساجد متماثية مع الأصالة و التراث.

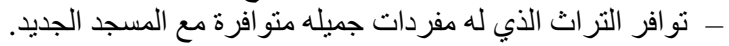

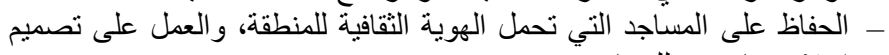

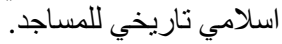
- المناطق المحيطة بالمسجد تحتاج إلى مظلات للصلاة والاهتمام بالنظافة بشكل أفضل . الفناط الحي - الحرص على تصميم عصري فيه أصالة الهوية التر اثية و التكنولوجيا. 


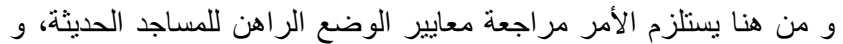

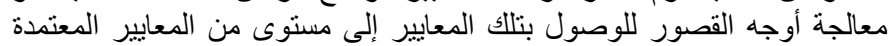

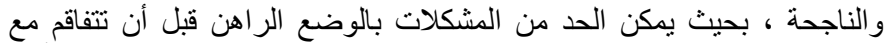

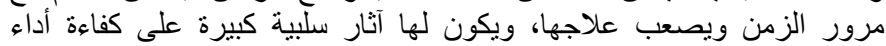

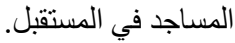

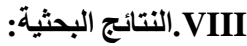

من خلال الإطار التطبيقي والمسح الميداني للبحث؛ أمكن تلخيص أهم النتائج

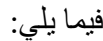
- يظهر من الدراسة التطبيقية على الرغم من اختلاف التشكيل العام للمسجدين

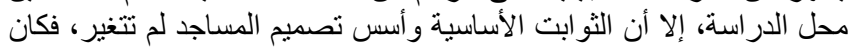

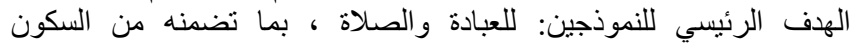

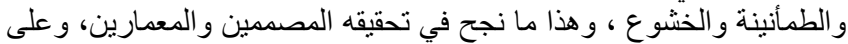

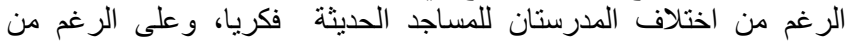

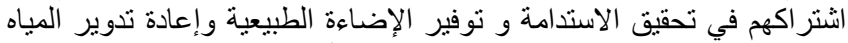

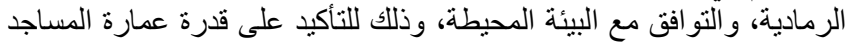

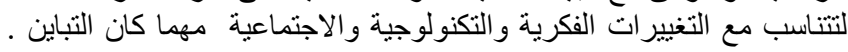

- إن التحول الجذري في عمارة المساجد المعاصرة ساهم بشكل نسبي، بفعالية

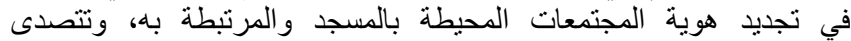

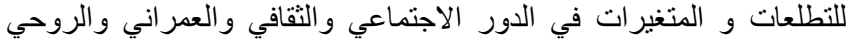

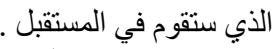
ــام قدرة عمارة المساجد المعاصرة على الاستمرارية للمفهوم المعماري

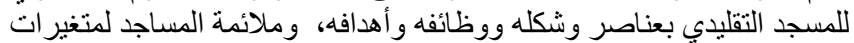

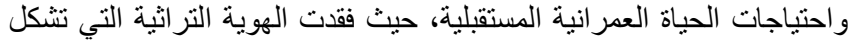
نموذجا تعبيريا عن هوية الأمة.

\section{- IX}

يمكن تلخيص بعض التوصيات التي تساهم في وصول مستقبل عمارة المسجد

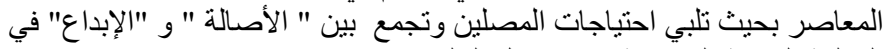
المملكة العربية السعودية.، من خلال التهات التالي:

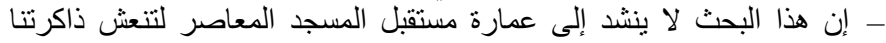

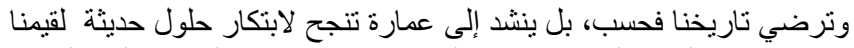

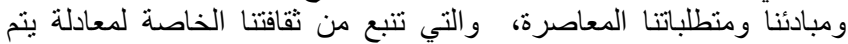

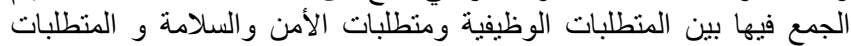

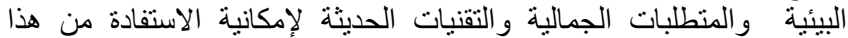
التطور لخدمة الهوية والقومية العربية والإسلامية.

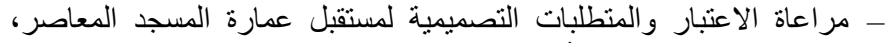

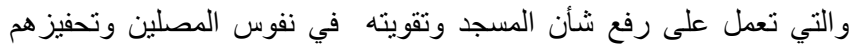

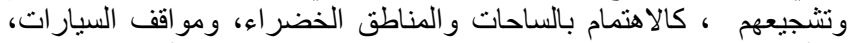

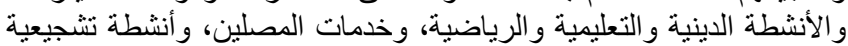
سو اء داخل المسجد أو محيطة به طبقا لخدية الخداتهم و احتباجاهم.

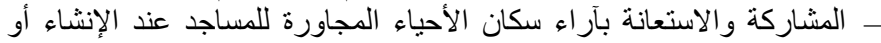

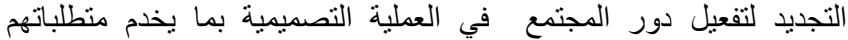
واحتياجاتهم حتى لا يتسبب في مشاكل مستقبلية فيما بعد، ويغير من رسالة

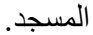

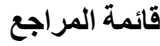

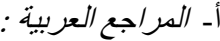

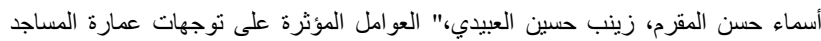

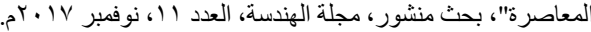

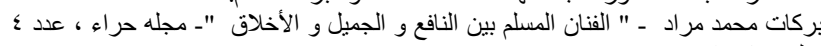

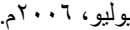
|جبر إبر اهيم، محمد إبر اهيم، "العمارة المصرية المعاصرة، المعطيات و النتاج"، الملتقى الدولي

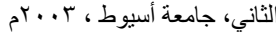

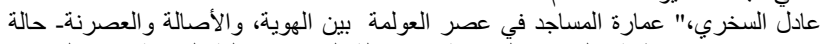

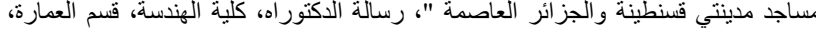

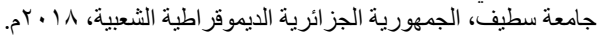

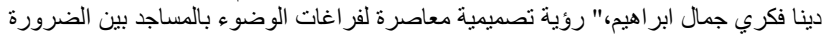

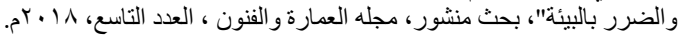

- تخصيص مناطق وخدمات مميزة لذوى الاحتياجات الخاصة جميعا بما فيها اصطحاب الأطفال

- المساعدة في ان يكون من خارج المسجد مظلات للمصلين ، و المناطق

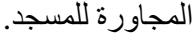

ص- معايير يمكن اقتراحها أو إعادة صياغتها بشكل مختلف من وجهة نظرك، التهائ

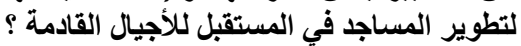

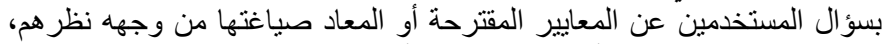

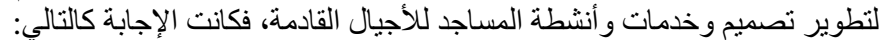

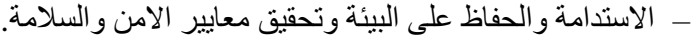

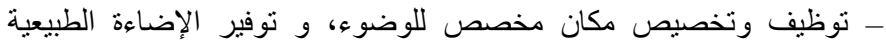

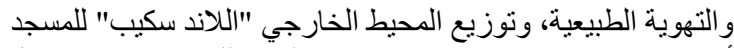

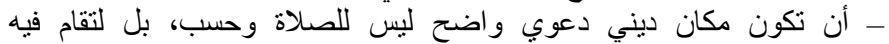

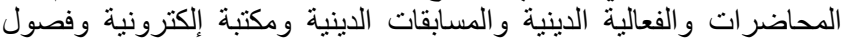

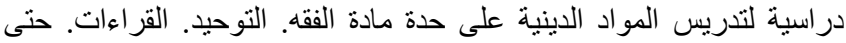

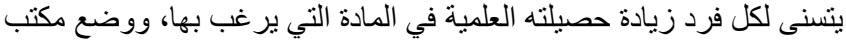
تطو عي في الاحياء ذات الكثافة السكانية.

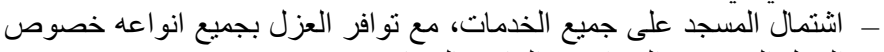
العزل الصوتي و الحر اري و المائي المباتي بالمساجد.

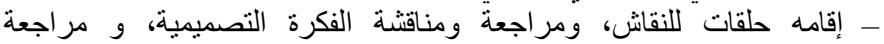

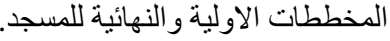

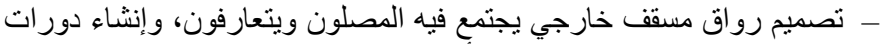

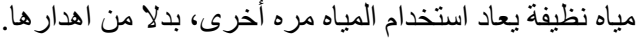

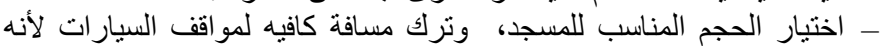

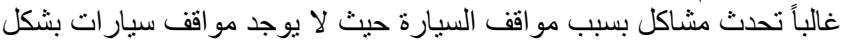

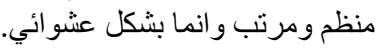

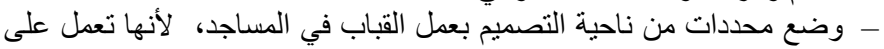

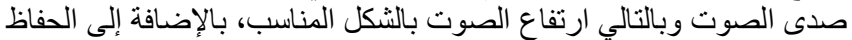
على العناصر الاسلامية القديمة.

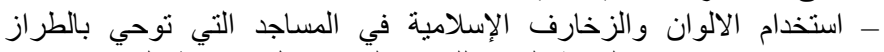

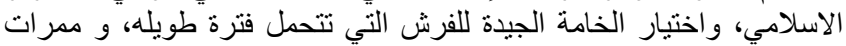

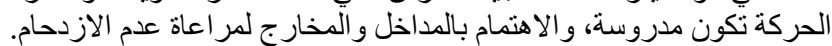
- مشاركة الطلاب بالر أبي المتو اجدين في المدارس القريبة من المساجد.

\section{ملخص نتائج الاستبيان التي تمت عرضها على المستخدمين كالترتيب التالي: VII}

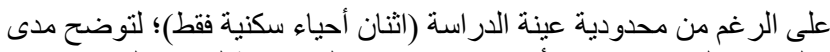

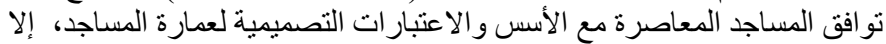

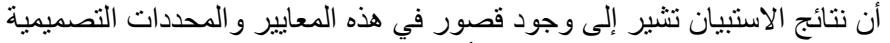
في الوضع الر اهن بالنسبة للمساجد بأحياء اللدراسة: في مدينة الرياض والئ والمدينة المنورة، من حيث:

- ضرورة توجيه الاهتمام للمساجد لتحقيق الوظيفة والكفاءة الدينية بشكل أفضل

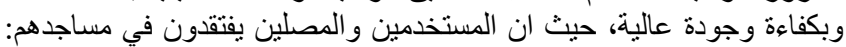

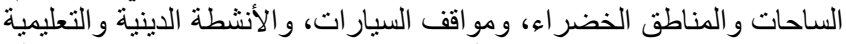

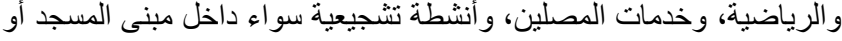
محيطة به ، وذللك لتحفز وتشجع المصلين على القدوم لممارسة الخدمات

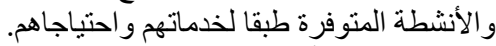

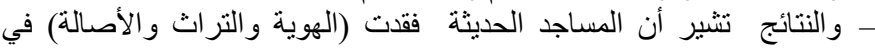

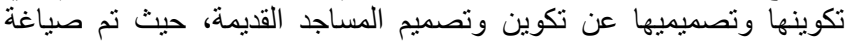

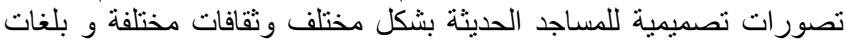

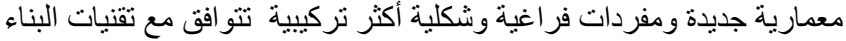

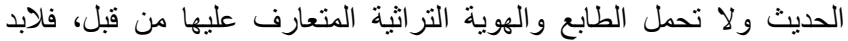

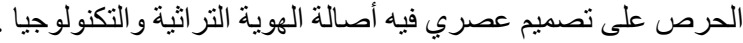
-

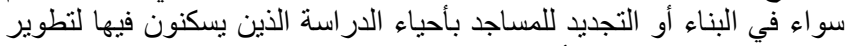

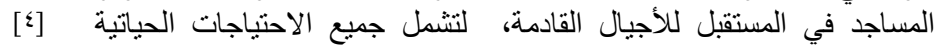

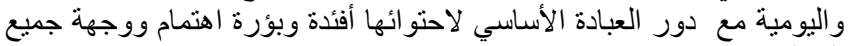


جانب المتطلبات: الوظيفية، والأمن و السلامة، والبيئية و الجمالية، بحيث تلبي احتياجات

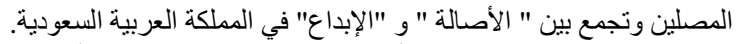

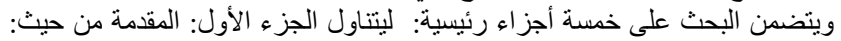

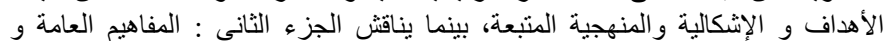

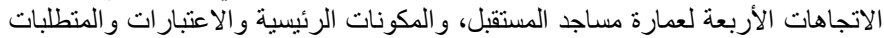

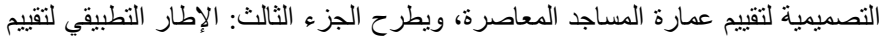

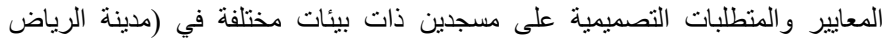

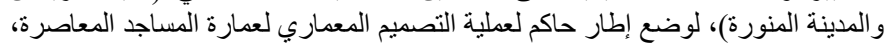

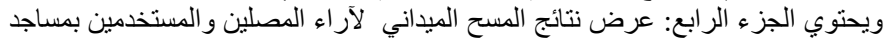

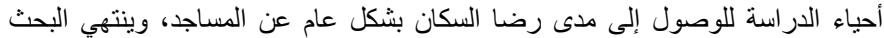

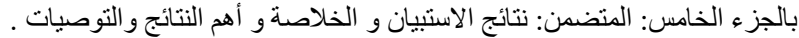

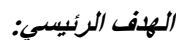
حصر وتوصيف دقيق لعمارة المساجد الحديثة بين التراث وات والهويـة والتطلعات المستقبلية

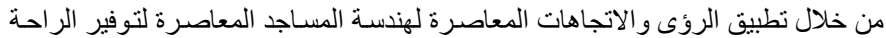
و التصميم البيئي لمستخدمين. الرون فئ. أهداف فرعية : النينية

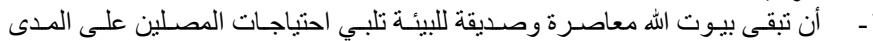

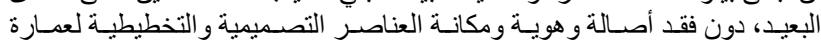

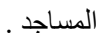

الالتزام بالنهج و الرؤى التصميمية والتخطيطية الإسلامية لمستقبل عمارة المساجد

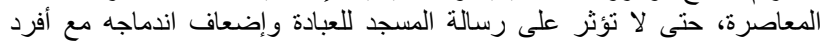

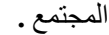

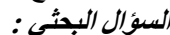

ما تأثير تطور التصميم المعماري المعاصر للمساجد الجديدة على احتر ام الهوية والأصالة

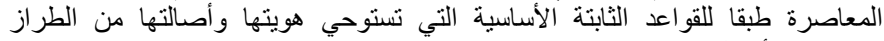

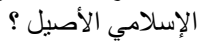

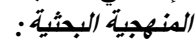

ينقسم البحث لتحقيق أهدافه على ثثلاث مناهج رئيسية:

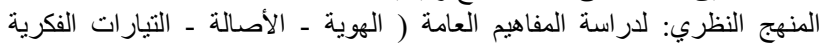

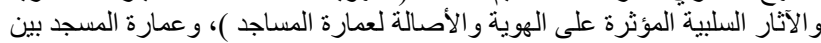

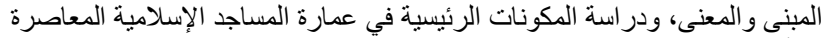

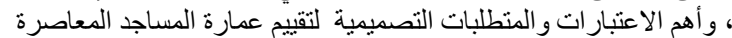

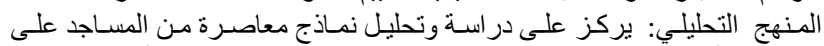

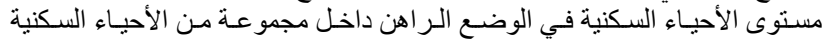

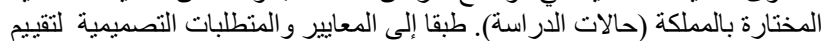

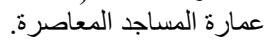

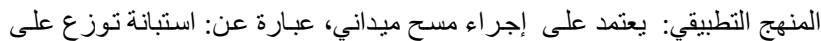

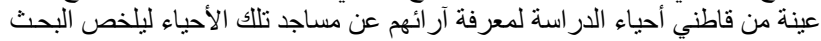

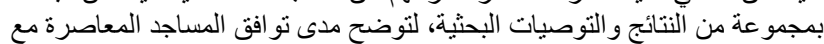

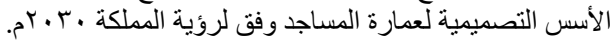

| شيماء عبد المجيد إبراهيه،" رصد وتحليل عمارة العصور الإسلامية وأثرها على العمارة

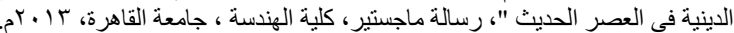

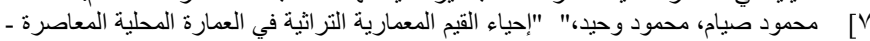

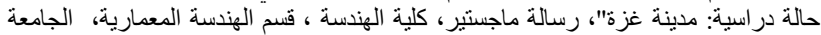

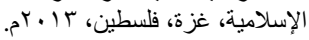

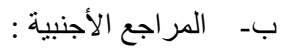

[8] Lacheheb, Sara, "Etude expérimentale de l'impact de la baie et de la composante réfléchie interne sur l'environnement lumineux intérieur: Cas des mosquées algériennes", Mémoire de magistère en Architecture, Option: Architecture, formes, ambiances, et développement durable, Encadré par Dr. Belakehal Azeddine, Département d'Architecture, Université Mohamed Khider - Biskra, 2013.

[9] United Nations, Popular Participation as a strategy for promoting community-level action and national development, report for the meeting held at United Nations headquarters, 1981.

\section{Title Arabic:}

\section{رؤى تصميمية لمستقبل عمارة المسجد المعاصر بين الهوية والأصالة}

\section{Arabic Abstract:}

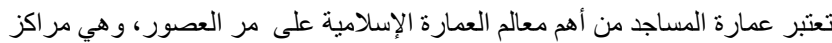

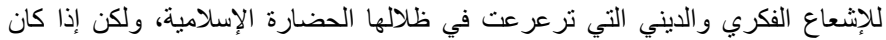

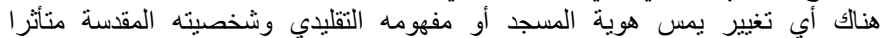

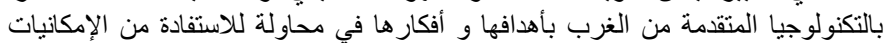

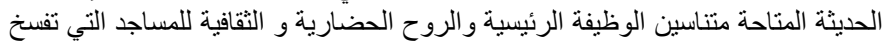

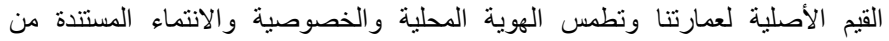
الموروث الحضاري للمدينة.

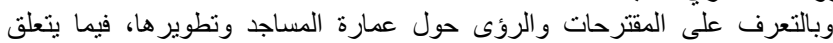

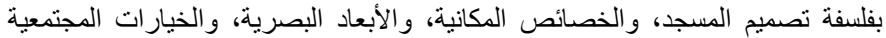

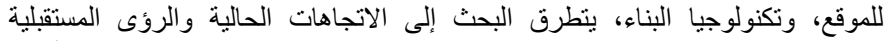

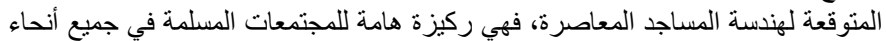

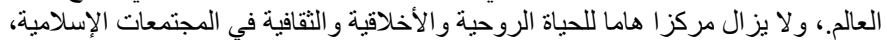

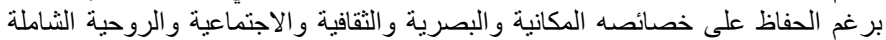

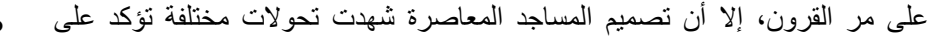
مركزتيه وقابليته للتكيف مع التطور ات ات المجنمعية الإسلامية.

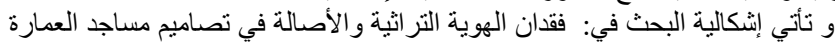
العربية و الإسلامية المعاصرة، والتي تتميز بضعف تصاميم العمارة المسجدية الجديدة من 